Chapter 10

\title{
Hydrotreating Catalytic Processes for Oxygen Removal in the Upgrading of Bio-Oils and Bio-Chemicals
}

\author{
Iñaki Gandarias and Pedro Luis Arias \\ Additional information is available at the end of the chapter \\ http://dx.doi.org/10.5772/52581
}

\section{Introduction}

In a future sustainable scenario a progressive transition by the chemical and energy industries towards renewable feedstock will become compulsory. Energy demand is expected to grow by more than $50 \%$ by 2035 [1], with most of this increase in demand emerging from developing nations. Clearly, increasing demand from finite petroleum resources cannot be a satisfactory policy for the long term. The transition to a more renewable production system is now underway; however, this transition needs more research and investment in new technologies to be feasible.

Biomass appears as the only renewable source for liquid fuels and most commodity chemicals [2]. This is the reason why, in the near future, bio-refineries in which biomass is catalytically converted to pharmaceuticals, agricultural chemicals, plastics and transportation fuels will take the place of petrochemical plants [3]. Indeed, biomass represents $77.4 \%$ of global renewable energy supply [4]. Current technologies to produce liquid fuels from biomass are typically multistep and energy-intensive processes, including the production of ethanol by fermentation of biomass derived glucose [5],bio-oils by fast pyrolysis or high pressure liquefaction of biomass [6,7], polyols and alkanes from hydrogenolysis of biomass derived sorbitol [8], and biodiesel from vegetable oils [9].Biomass can also be gasified to produce CO and $\mathrm{H}_{2}$ (synthesis gas), which can be further processed to produce methanol or liquid alkanes through Fischer-Tropsch synthesis [10].

The so-called "First Generation" biofuels, such as sugarcane ethanol in Brazil, corn ethanol in US, oilseed rape biodiesel in Germany, and palm oil biodiesel in Malaysia,already present mature commercial markets and well developed technologies. Nonetheless, there is a worldwide increasing awareness against the use of edible oils and seeds to generate transportation fuels, and critical voices have aroused questioning the actual sustainability of these 
"First Generation" biofuels. In fact, nowadays $95 \%$ of biodiesel is made from edible oil [9]. This means that possible food resources are being used as automotive fuels when some part of the World's population is suffering from hunger. Therefore, large-scale production of biodiesel from edible oils may bring about a global imbalance in the food supply market. Another significant concern of using "First Generation" technologies is the deforestation and the destruction of ecosystems. Indeed, the expansion of oil-crop plantations for biofuel production on a large scale has caused deforestation in countries such as Malaysia, Indonesia and Brazil because more and more forest has been cleared for plantation purposes. In addition to this, in developing countries energy crops are powerful competitors for scarce water resources [11].

Being the non-edible portion of the plant and the most abundant source of biomass, lignocellulosic biomass materials are attracting growing attention as sustainable and renewable energy sources. The so-called "Second Generation" technologies for the production of fuels and chemicals can use a wide range of lignocellulosic biomass residues such as agricultural, industrial, and forest wastes, and also energy crops (willow, switchgrass) that do not compete with food crops for available land. The average composition of lignocellulosic material is as follows: $50 \%$ cellulose, $25 \%$ hemicellulose, and $20 \%$ lignin [12]. Cellulose is a linear polysaccharide with $\beta-1,4$ linkages of D-glucopyranose monomers (Figure 1). Hemicellulose is a more complex polymer containing five different sugar monomers: five carbon sugars (xylose and arabinose) and six carbon sugars (galactose, glucose, and mannose). Lignin is a highly branched aromatic polymer, that consists of an irregular array of variously bonded "hydroxy-" and "methoxy-" substitutedphenylpropane units. Lignin is mainly found in woody biomass. Lignocellulosic materials can be converted into liquid fuels by three primary routes, including (i) syngas production by gasification, (ii) bio-oil production by pyrolysis or liquefaction, and (iii) acid hydrolysis reactions [13].

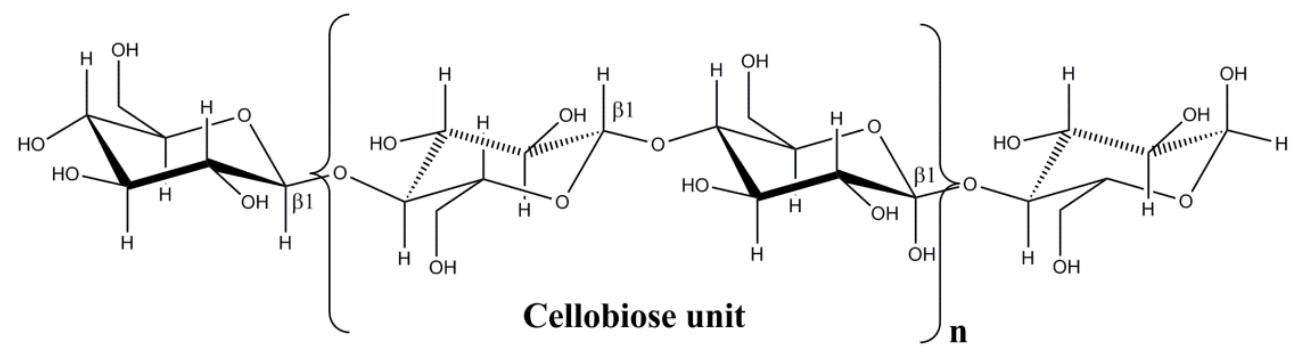

Figure 1. Chemical structure of cellulose.

In the pyrolysis process, biomass feedstock is heated in the absence of oxygen, forming a gaseous product, which after cooling condenses. Depending on the operating conditions that are used, pyrolysis processes are known as slow or fast pyrolysis. Fast pyrolysis processes are characterized by high rates of particle heating (heating rate $>1000^{\circ} \mathrm{C} / \mathrm{min}$ ) to temperatures around $500^{\circ} \mathrm{C}$, and rapid cooling of the produced vapors to condense them (vapor 
residence time $0.5-5 \mathrm{~s}$ ). In order to obtain that fast heating rates, it is essential to use reactors that provide high external heat transfer (such as fluidized bed reactors) and to guarantee an efficient heat transfer through the biomass particle, using biomass particle size of less than 5 $\mathrm{mm}$ [7]. Fast pyrolysis produce $60-75 \mathrm{wt} \%$ of liquid bio-oil, $15-25 \mathrm{wt} \%$ of solid char, and $10-20 \mathrm{wt} \%$ of non condensable gases, depending on the feedstock. In slow pyrolysis biomass is heated to around $500^{\circ} \mathrm{C}$ at much lower heating rates than those used in fast pyrolysis. The vapor residence times are much longer; they vary from $5 \mathrm{~min}$ to $30 \mathrm{~min}$. As a consequence of the lower heating rate and of the longer vapor residence time, lower yields to pyrolysis oils and higher yields to char and gas products are obtained (Figure 2). As a result of all this, for bio-oil production from biomass, fast pyrolysis processes are preferred.

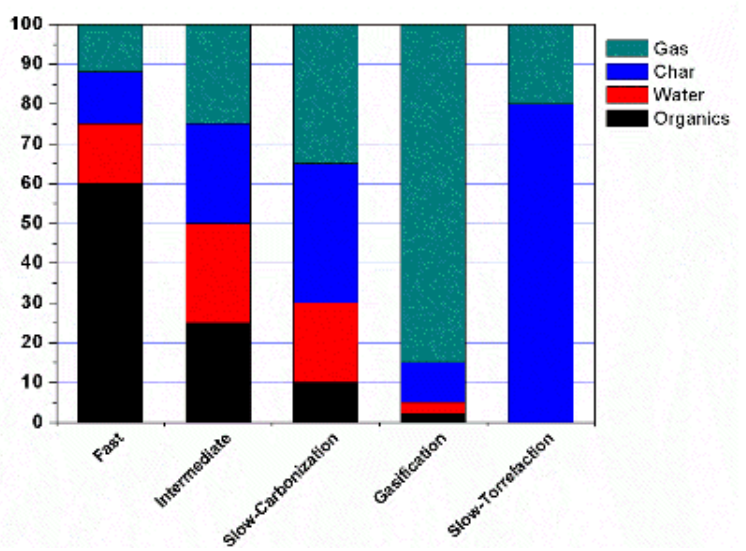

Figure 2. Product spectrum from pyrolysis. Data from [14].

Bio-oils are dark-red brown color liquids. They are also known as pyrolysis oils, bio-crude oil, wood oil or liquid wood. Bio-oils usually have higher density, viscosity and oxygen content compared to fuel-oil. While the sulfur and nitrogen content is usually smaller (Table 1). The high oxygen content of bio-oils generates some negative characteristics like low heating value (HV), immiscibility with conventional fuels and high viscosity. A serious problem of bio-oils is their instability during storage, as their viscosity, HV and density are affected. This is because some of the organic compounds present in bio-oils are highly reactive. For instance, ketones, aldehydes and organic acids react to form ethers, acetals and hemiacetals respectively [15]. Therefore, bio-oils need to be upgraded to reduce their oxygen content in order to increase their stability, to be miscible with conventional oil, and to increase their $\mathrm{H} / \mathrm{C}$ ratio. This upgrading can be carried out through three different routes: (i) catalytic hydrotreating, usually known as hydrodeoxygenation (HDO), which consists mainly on decarboxylation, hydrocracking, hydrogenolysis and hydrogenation reactions, (ii) zeolite upgrading or (iii) through esterification reactions. Zeolite upgrading is carried out without external hydrogen sources, and therefore the resulting oil has lower HV and H/C than conventional fuels. Esterification can significantly increase the chemical and physical properties 
of bio-oil, however it requires using high amounts of alcohols, which are highly demanded. Catalytic hydrotreating appears to have the greatest potential to obtain high grade oils which are compatible with the already available infrastructure for fossil fuels.

\begin{tabular}{ccc}
\hline Property & Pyrolysis Oil & Heavy Oil \\
\hline Moisture Content, wt \% & $15-30$ & 0.1 \\
\hline pH & 2.5 & \\
\hline Elemental Composition, wt \% & 85 \\
\hline Carbon & $54-58$ & 11 \\
\hline Hydrogen & $5.5-7.0$ & 1.0 \\
\hline Oxygen & $35-40$ & 0.3 \\
\hline Nitrogen & $0-0.2$ & 0.1 \\
\hline Ash & $0-0.2$ & 40 \\
\hline Higher Heating Value, MJ/kg & $16-19$ & 180 \\
\hline Viscosity (50 $\left.{ }^{\circ} \mathrm{C}\right), \mathrm{cP}$ & $40-100$ & 1 \\
\hline Solids (wt\%) & $0.2-1.0$ & \\
\hline
\end{tabular}

Table 1. Typical Properties of Wood Pyrolysis Bio-Oil, and Heavy Fuel Oil [13].

Not only fuels, but also commodity chemicals are nowadays derived from petroleum-based resources. Commodity chemicals are involved in the production of a wide variety of products and thus are an essential and integral part of the modern societies. Hence, in the search for a sustainable scenario, it is crucial to also look towards alternative biorenewable sources for these chemicals. In the case of platform chemicals coming from biomass, such as glucose, levulinic acid, 5-(hydroxyl-methyl furfural), sorbitol, or glycerol,they usually have higher $\mathrm{O} / \mathrm{C}$ ratio than most commodity chemicals. Therefore, the conversion of these platform chemicals into value-added chemicals usually requires $\mathrm{O}$ removal reactions.

This book chapter summarizes the main aspects involved in the catalytic hydrotreating processes for the oxygen removal from bio-oils and from biomass based platform chemicals.

\section{Hydrotreating catalytic processes in bio-oil upgrading}

As it has been stated in the introduction, a general characteristic of bio-oils coming from the pyrolysis of biomass is their high oxygen content (35-40 wt\%). More than 300 compounds have been identified in bio-oil, most of them containing oxygen atoms. The exact composition of the bio-oil depends on the type of biomass fed. These compounds can be classified in five broad categories: (i) hydroxyaldehydes, (ii) hydroxyketones, (iii) sugars and dehydrosugars, (iv) carboxylic acids, and (v) phenolic compounds [16]. Hydroprocessing of biomass- 
derived oils differs from processing petroleum because of the importance of deoxygenation as compared to nitrogen or sulfur removal. Bio-oil hydrodeoxygenation (HDO) process implies complex reaction networks that includes cracking, decarbonylation, decarboxylation, hydrocracking, hydrogenolysis, hydrogenation and polymerization. The upgrading process should yield a product with lower amount of water and oxygen, decreased acidity and viscosity, and higher HV. The complexity of the reactions and the high variety of oxygenated compounds make the evaluation of bio-oil upgrading difficult and has brought the use of model compounds such as phenol, guaicol, 2-ethylphenol, methyl heptanoate or benzofuran to test different catalysts and to understand the main characteristics of the HDO process. Elliot [17] has reported the HDO reactivity of different organic compounds that are typically present in bio-oils (see Figure 3). Olefins, aldehydes and ketones can easily be reduced by $\mathrm{H}_{2}$ at temperatures as low as $150-200{ }^{\circ} \mathrm{C}$. Alcohols react at $250-300{ }^{\circ} \mathrm{C}$ by hydrogenation and thermal dehydration to form olefins. Carboxylic and phenolic ethers react at around $300{ }^{\circ} \mathrm{C}$. Regarding the operating pressures, due to the low solubility of hydrogen in organic and aqueous solutions, high pressures are required to guarantee high availability of hydrogen in the vicinity of the catalyst (80-300 bar of $\mathrm{H}_{2}$ pressure) [15].

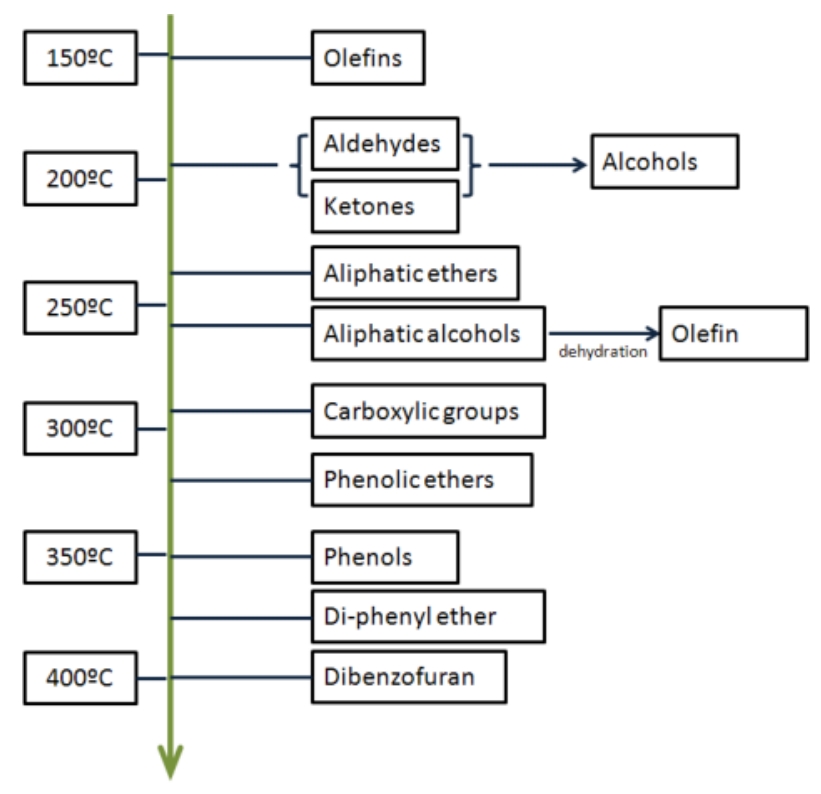

Figure 3. Reactivity scale of organic components under HDO conditions. Adapted from [17].

\subsection{Catalysts and reaction mechanisms}

HDO is a process closely related to hydrodesulphurization (HDS), which is highly developed in the oil-refinery industry. In both processes, hydrogen is used to remove the heteroa- 
tom in the form of $\mathrm{H}_{2} \mathrm{O}$ and $\mathrm{H}_{2} \mathrm{~S}$ respectively. This is the reason why several works on bio-oil HDO use catalytic systems already used in HDS processes, such as Co-Mo or Ni-Mo based catalysts. These catalysts are active in their sulphide form, so they need to be pretreated with $\mathrm{H}_{2} \mathrm{~S}$ before operation to obtain $\mathrm{Co}-\mathrm{MoS}_{2}$ or Ni-MoS active sites. Romero et al. [18] using $\mathrm{Co}_{-} \mathrm{MoS}_{2}$ type catalysts for the HDO of 2-ethylphenol at $340^{\circ} \mathrm{C}$ and $7 \mathrm{MPa}$ of hydrogen pressure proposed the reaction mechanism described in Figure 4. It is suggested that the oxygen from the molecule adsorbs on a vacancy of a $\mathrm{MoS}_{2}$ matrix. At the same time, the $\mathrm{H}_{2}$ from the feed dissociatively adsorbs on the catalyst surface forming S-H species. The addition of a proton to the adsorbed oxygenated molecule leads to an adsorbed carbocation. This intermediate can directly undergo a $\mathrm{C}-\mathrm{O}$ bond cleavage and the aromatic ring is regenerated leading to ethylbenzene. The vacancy is afterwards recovered by elimination of water.

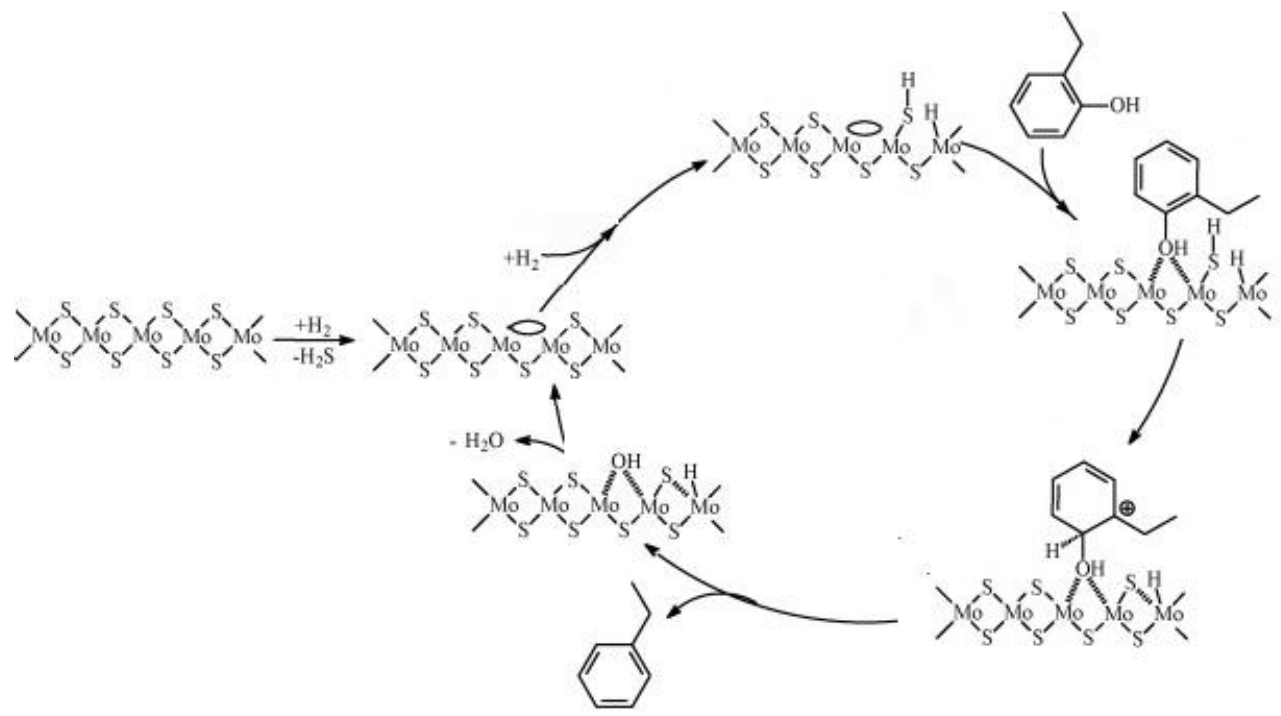

Figure 4. Proposed mechanism of HDO of 2-ethylphenol over a schematic Co-MoS 2 catalyst Adapted from [18].

The problem of using $\mathrm{MoS}_{2}$ type catalysts for HDO of bio-oils is that during prolonged operation sulfur stripping and oxidation of the surface of the catalyst occurs, causing deactivation of the catalyst. The reason is that as compared to conventional oil, the sulfur content of bio-oil is very low (less than $0.1 \mathrm{wt} \%$ [19]). One alternative to avoid this problem is the cofeeding of $\mathrm{H}_{2} \mathrm{~S}$ to the system, in order to regenerate the sulfide sites. For instance, in the $\mathrm{HDO}$ of alyphatic esters over a $\mathrm{CoMoS}_{2} / \mathrm{Al}_{2} \mathrm{O}_{3}$ and $\mathrm{NiMoS}_{2} / \mathrm{Al}_{2} \mathrm{O}_{3}$ catalysts a promoting effect was observed in the activity of the catalyst when co-feeding $\mathrm{H}_{2} \mathrm{~S}$, however this co-feeding did not prevent from catalyst deactivation. This promoting effect was related to the increase in Brönsted acidity in the presence of $\mathrm{H}_{2} \mathrm{~S}$ [20]. Nonetheless, the use of $\mathrm{H}_{2} \mathrm{~S}$ has also some drawbacks. In the $\mathrm{HDO}$ of phenol over a Ni-MoS$-\mathrm{Al}_{2} \mathrm{O}_{3}$ catalyst, it was observed an 
inhibitory effect of $\mathrm{H}_{2} \mathrm{~S}$, leading to a decrease in phenol conversion and not preventing catalyst deactivation. This was ascribed to the competitive adsorption between phenol and $\mathrm{H}_{2} \mathrm{~S}$ [21]. Moreover, the formation of sulfur-containing compounds such as dimethyl sulfide, diheptyl sulfide, hexanethiol and heptanethiol was observed in the HDO of aliphatic oxygenates over $\mathrm{Co}-\mathrm{MoS}_{2}$ catalysts, even in the absence of sulfiding agents [22]. Therefore, the use of $\mathrm{MoS}_{2}$ type catalysts in bio-oil HDO seems challenging, becouse sulfur free bio-oil can be contaminated by sulfur, and because wood-based bio-oils contain high amounts of phenolic compounds that would compete with $\mathrm{H}_{2} \mathrm{~S}$ for the active sites of the catalyst.

Another alternative is the use of bi-functional catalysts formed by the combination of transition metals and oxophilic metals, such as $\mathrm{MoO}_{3}, \mathrm{Cr}_{2} \mathrm{O}_{3}, \mathrm{WO}_{3}$ or $\mathrm{ZrO}_{2}$. In this case, the oxophilic metal acts as a Lewis acid site. The oxygen ion pair of the target molecule is attracted by the unsaturated oxophilic metal. The second step of the mechanism is hydrogen donation. In this case, the hydrogen molecule is dissociatively adsorbed and activated on the transition metal. Finally, the activated hydrogen is transferred to the adsorbed molecule.

Regarding the support, $\gamma-\mathrm{Al}_{2} \mathrm{O}_{3}$ is the most commonly used one. Nonetheless, it has to be taken into account the structural changes that $\gamma-\mathrm{Al}_{2} \mathrm{O}_{3}$ might suffer under the typical operating conditions in HDO. In contact with hot water $\left(\mathrm{T}>350^{\circ} \mathrm{C}\right), \gamma-\mathrm{Al}_{2} \mathrm{O}_{3}$ is converted into a hydrated boehmite $(\mathrm{AlOOH})$ phase with a significant decrease in the acidity and surface area [23]. Moreover, the relatively high surface acidity of $\mathrm{Al}_{2} \mathrm{O}_{3}$ is thought to promote the formation of coke precursors. In fact, coke formation is one the main factors affecting the stability of the catalyst. Therefore, the use of less acidic or neutral support like active carbon or $\mathrm{SiO}_{2}$ is an interesting alternative [24]. For instance, Echeandia et al. [25] using $\mathrm{Ni}-\mathrm{WO}_{3}$ on active carbon for the $\mathrm{HDO}$ of $1 \mathrm{wt} \%$ phenol in n-octane at $150-300^{\circ} \mathrm{C}$ and 15 bar observed lower coke formation on the surface of the active carbon with respect to alumina support. Based on product analysis, they also concluded that HDO of phenol occurs via two separate pathways: one leading to aromatics through a direct hydrogenolysis route, and the other one to cyclohexane, through a hydrogenation-hydrogenolysis route (see Figure 5). In terms of obtaining a final product with high octane number and reducing the consumption of hydrogen, direct hydrogenolysis reaction is preferred. Nonetheless, aromatics are harmful to human health and its content in transportation fuels is limited by legislation. Therefore, it is important to understand which sites are responsible of each route, in order to obtain an upgraded product with the desired aromatic content. $\mathrm{CeO}_{2}$ and $\mathrm{ZrO}_{2}$ supports have also shown to give good results in the HDO of different molecules. $\mathrm{ZrO}_{2}$-supported noble metal catalysts ( $\mathrm{Rh}, \mathrm{Pd}$ and $\mathrm{Pt}$ ) [26] were compared with the conventional sulfided $\mathrm{CoMo} / \mathrm{Al}_{2} \mathrm{O}_{3}$ catalyst in the $\mathrm{HDO}$ of Guaiacol in the presence of $\mathrm{H}_{2}$ at $300{ }^{\circ} \mathrm{C}$. Sulfided $\mathrm{CoMo} / \mathrm{Al}_{2} \mathrm{O}_{3}$ deactivated due to carbon deposition, and the products were contaminated with sulfur, however, neither problem was observed with the $\mathrm{ZrO}_{2}$-supported noble metal catalysts. As a conclusion, a good support for HDO should provide high affinity for the oxygen-containing molecule while presenting moderate acidity in order to minimize the formation of coke deposits. 


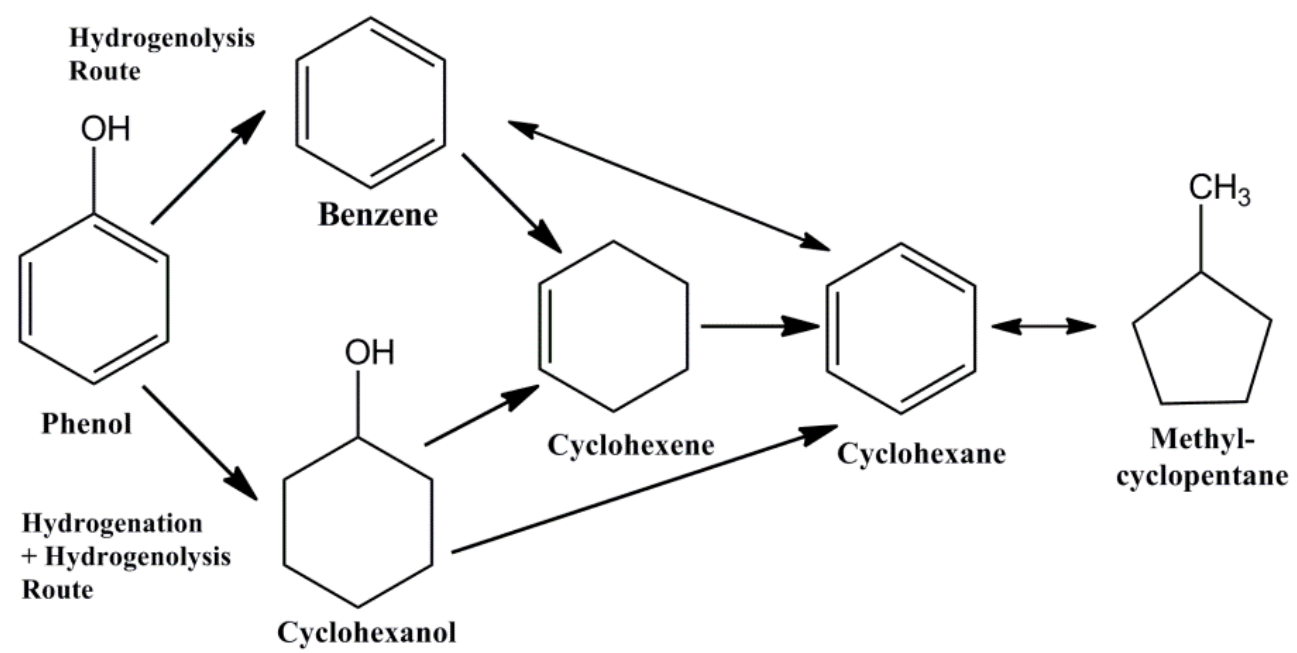

Figure 5. Scheme of phenol HDO. Adapted from [25].

\subsection{Upgrading of real bio-oils}

An important aspect in the HDO of bio-oils is the required degree of deoxygenation. It is assumed that the upgraded oil should contain less than $5 \mathrm{wt} \%$ oxygen so that the viscosity is decreased to that required for fuel applications [17]. However, during the hydrotreating, not only the oxygen is removed in the form of water, but also the saturation of double bounds occurs. This saturation has two significant negative effects. The first one is related to the quality of the upgraded oil, because the saturation of the aromatic components has a highly detrimental effect in the octane number. For instance, the octane number of toluene (119) decreases to 73 when the aromatic ring is hydrogenated [10]. The second negative effect is related to the consumption of hydrogen. According to Venderbosh et al. [27] in order to achieve $50 \%$ of deoxygenation $16 \mathrm{~g} \mathrm{H}_{2} / \mathrm{Kg}$ of bio-oil is required, which is close to the expected stoichiometry value. Nonetheless, if the aim is to obtain the total removal of oxygen, the $\mathrm{H}_{2}$ consumption increases to $50 \mathrm{~g} \mathrm{H}_{2} / \mathrm{Kg}$ of bio-oil; which means that the $\mathrm{H}_{2}$ consumption is $56 \%$ higher than the stoichiometry value. Some other studies suggest even higher $\mathrm{H}_{2}$ consumption requirements, $62 \mathrm{~g} \mathrm{H}_{2} / \mathrm{Kg}$ of bio-oil [28]. This deviation of the $\mathrm{H}_{2}$ consumption from the stoichiometry value is explained on the basis of the different reactivity of the oxygenated compounds present in the bio-oil. High reactive compounds, such as ketones, are easily converted with low hydrogen consumption. However, more complex molecules, such as phenols, might suffer the hydrogenation/saturation of the molecule and therefore the hydrogen consumption exceeds the stoichiometric prediction at the high degree of deoxygenation.

In order to obtain high degrees of HDO but minimizing the hydrogenation of aromatics in bio-oil, two step hydrogenating processes have been developed. In the first stage, high reac- 
tive and unstable compounds are transformed into more stable ones at low temperature $\left(270^{\circ} \mathrm{C}, 136 \mathrm{~atm} \mathrm{H}_{2}\right)$ and without a catalyst. In the second step, a deeper HDO is carried out at higher temperatures $\left(400^{\circ} \mathrm{C}, 136 \mathrm{~atm} \mathrm{H}_{2}\right)$ and using hydrotreating catalysts. The two-step hydrotreatment allows $13 \%$ reduction in hydrogen consumption for equivalent oil yield. Nonetheless, the reported octane number of the upgraded bio-oil, 72, is still lower than that of gasoline [17].

Environmental aspects should also be taken into account. Aromatic compounds have on one hand high octane number; however, they are also harmful to health. Indeed, environmental standards for aromatics in transportation fuels are becoming more restrictive. Thus, it seems challenging to achieve an agreement between obtaining oils with high octane number while fulfilling aromatic content policies.

\section{Hydrogenolysis reactions in the valorization of platform chemicals}

Biomass components have a great potential as building block intermediates. Indeed, sugars, vegetable oils and terpenes can be employed for synthesizing products with a high added value, such as chemicals and fine chemicals. There are hundreds of different processes to obtain chemicals from biomass origin building blocks. This chapter deals with those processes involving hydrotreating for the removal of oxygen. In the first part of this section, some examples of significant hydrogenolysis reactions in the valorization of platform chemicals will be given, while the last part will be focused on one of the most studied hydrogenolysis proccesses; the conversion of glycerol into propanediols (PDO).

As it has been previously stated, platform chemicals coming from biomass usually contain higher $\mathrm{O} / \mathrm{C}$ ratio than most commodity chemicals; thus main valorization processes require the removal of oxygen. One widely used process to remove oxygen is hydrogenolysis. Hydrogenolysis is a type of reduction that involves chemical bond dissociation in an organic substrate and simultaneous addition of hydrogen to the resulting molecular fragments [33]. Therefore, reaction for oxygen removal involves the cleavage of the $\mathrm{C}-\mathrm{O}$ bond and the addition of hydrogen (oxygen is removed in the form of $\mathrm{H}_{2} \mathrm{O}$ ). This is a significant aspect, because, in those processes where the starting and target molecule have the same number of carbons it is important to use catalytic systems that present high activity in C-O bond hydrogenolysis while low activity in C-C bond hydrogenolysis.

\subsection{Hydrogenolysis of sugars}

Two types of sugars are present in biomass: hexoses (six-carbon sugars), of which glucose is the most common one, and pentoses (five-carbon sugars), of which xylose is the most common one. Glucose and xylose can be easily hydrogenated to yield sorbitol [29] and xylitol [30] respectively. These two molecules can undergo C-C and C-O hydrogenolysis in the presence of hydrogenation catalysts, leading mainly to a mixture of ethyleneglycol, glycerol, and 1,2-propanediol. Other products such as butanediols, lactic acid, methanol, ethanol, and propanol can also be formed (Figure 6). Ni is known to show high hydrogenolysis activity 
towards $\mathrm{C}-\mathrm{C}$ and $\mathrm{C}-\mathrm{O}$ bond hydrogenolysis, this is the reason why, the use of Ni on different acid supports seems an interesting alternative for this process. For instance, Ni supported on $\mathrm{NaY}$ zeolite gave $68 \%$ sorbitol conversion with $75 \%$ combined selectivity to 1,2-PDO and glycerol at $220^{\circ} \mathrm{C}$ and 60 bar $\mathrm{H}_{2}$ pressure after $6 \mathrm{~h}$ [8]. The addition of $\mathrm{Pt}$ to the catalyst did not influence its activity and selectivity significantly. However, in the case of $20 \mathrm{wt} \%$ $\mathrm{Ni} / \mathrm{Al}_{2} \mathrm{O}_{3}$ prepared by coprecipitation, the addition of $0.5 \mathrm{wt} \%$ of Ce significantly increased sorbitol conversion (from $41 \%$ to $91 \%$ ) and the stability of the catalyst [31]. It seems that the addition of Ce considerably reduces Ni leaching, and hence improves the stability of the catalyst. Other catalytic systems have also been reported besides the $\mathrm{Ni}$ acid-support ones. For instance, $\mathrm{Ru}$ supported on carbon nanofiber and graphite felt composite catalysts gave $68 \%$ sorbitol conversion and $79 \%$ propylene glycol selectivity at $220^{\circ} \mathrm{C}$ and $8.0 \mathrm{MPa}$ hydrogen pressure [32].

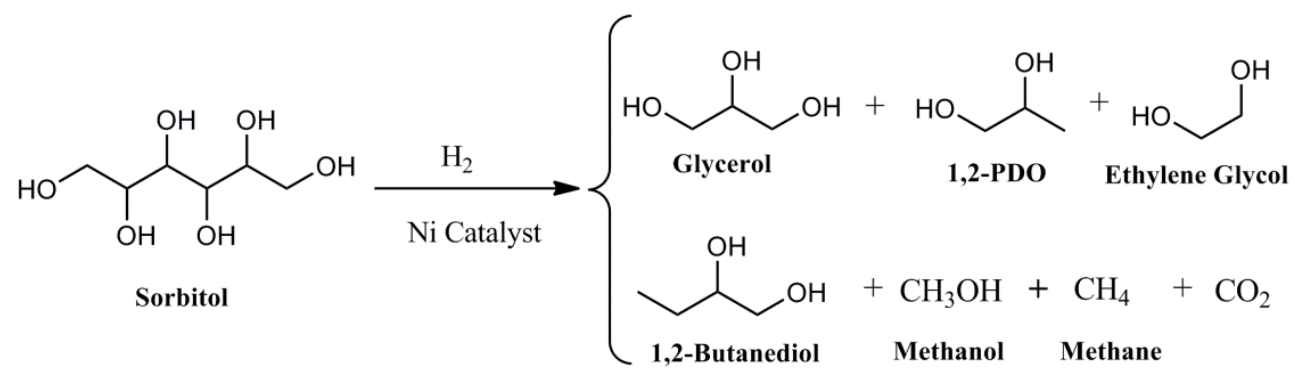

Figure 6. Reaction products of catalytic hydrogenolysis of sorbitol over supported Ni catalyst in the aqueous phase. Adapted from [31].

\subsection{Hydrogenolysis of 5-Hydroxymethyl-Furfural (HMF)}

5-Hydroxymethyl-furfural (HMF) can be obtained in a biphasic reactor from the acid-catalyzed dehydration of hexoses[33]. HMF by itself cannot be used as motor fuel due to its high boiling point $\left(283^{\circ} \mathrm{C}\right)$. However, it can be transformed to 2,5-dimethylfuran (DMF) through a two consecutive hydrogenolysis reactions (see Figure 7). DMF not only decreases the boiling point to a value suitable for liquid fuels, but also attains the lowest water solubility and the highest octane number ( $\mathrm{RON}$ ) of the mono-oxygenated $\mathrm{C}_{6}$ compounds, while preserving a high energy density $30 \mathrm{~kJ} \mathrm{~cm}^{-3}$, which is $40 \%$ higher that the energy density of bio-ethanol and comparable to the one of gasoline $\left(35 \mathrm{KJ} \mathrm{cm}^{-3}\right)$ [34]. Roman-Leshkov et al. [34] used $\mathrm{CuRu} / \mathrm{C}$ catalysts (prepared by incipient wetness impregnation) in a flow reactor using $5 \mathrm{wt}$ $\% \mathrm{HMF}$ in a 1-butanol solution at $220^{\circ} \mathrm{C}$ and 6.8 bar $\mathrm{H}_{2}$ pressure. Yields to DMF of $71 \%$ were measured. An important aspect in their process is that the catalyst should be chloride-resistant, because, $\mathrm{NaCl}$ was used in the dehydration step of hexoses to HMF to increase their solubility in water. Very recently, Luijkx et al. [35] reported the production of 2,5-DMF by the hydrogenolysis of 5-HMF over a Pd/C catalyst in 1-propanol. Due to simultaneous alcoholysis, significant amount of ethers products were formed. 


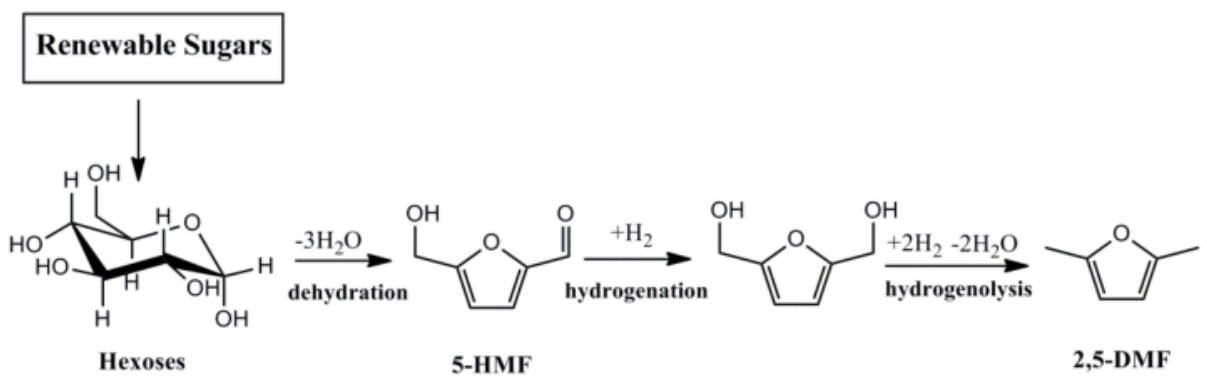

Figure 7. Reaction scheme for the conversion of sugars into 2,5-dimethylfuran. Adapted from [36]

\subsection{Hydrotreating of vegetable oils and hydrogenolysis of fatty acids}

Biodiesel is currently obtained from the transesterification reaction of vegetable oils. A possible drawback of this technology is that large investment is required to build up new biodiesel plants. An interesting alternative is to directly feed the vegetable oil into the hydrotreating unit of a petroleum refinery, for instance, vegetable oil can be co-fed with heavy vacuum oil $\mathrm{HVO}$. Under typical hydrotreating conditions $\left(300-450^{\circ} \mathrm{C}, 50 \mathrm{bar}_{2}\right.$ pressure, sulfided $\mathrm{NiMo} / \mathrm{Al}_{2} \mathrm{O}_{3}$ catalyst), vegetable oils are transformed into alkanes through three different pathways: decarboxylation, decarbonylation and HDO. The straight chain alkanes can undergo isomerization and cracking to produce lighter and isomerized alkanes (Figure 8) [37]. It was reported that mixing the sunflower oil with HVO does not decrease the rate of desulfurization. Moreover, the rate of vegetable oil hydrotreating is faster that the rate of HVO desulfurization. For industrial application, corrosion problems should be taken into account and the formation of waxes should be minimized, as they can plug the reactor.

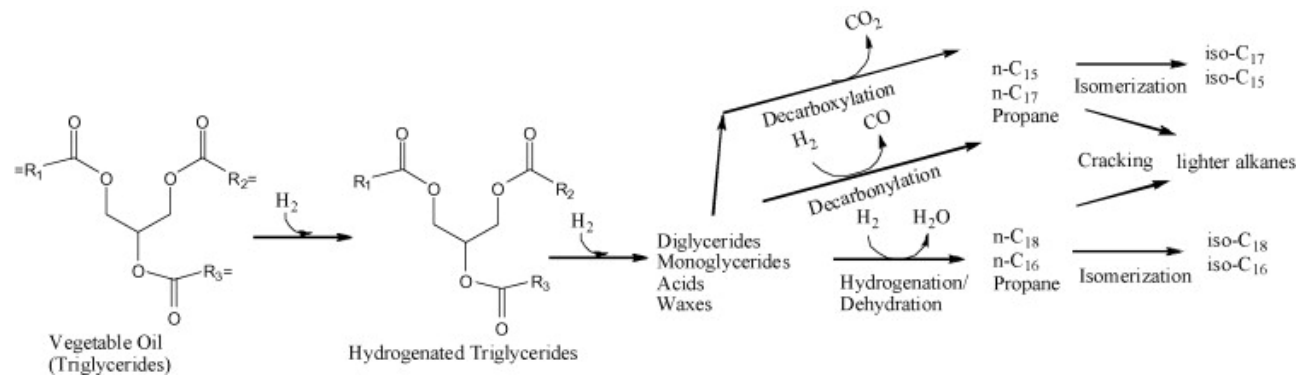

Figure 8. Reaction pathway for conversion of tri-glycerides to alkanes [37].

Fatty alcohols can be obtained by catalytic hydrogenolysis of fatty acid methyl esters. Smallchain fatty alcohols are used in cosmetics and food and as industrial solvents or plasticizers, while the large-chain fatty alcohols are important as biofuels and as nonionic surfactants or 
emulsifiers. Fatty alcohols are produced by hydrogenolysis, in the presence of $\mathrm{Cu}$ based heterogeneous hydrogenation catalysts, operating under $\mathrm{H}_{2}$ pressures between 20 and 30 bar and temperatures in the range of $97-197^{\circ} \mathrm{C}$ [38]. High hydrogen pressures are required to increase the solubility of hydrogen in the reaction mixture, in order to boost the availability of $\mathrm{H}_{2}$ at the catalyst surface and to reduce mass transport limitations [39].The stoichiometry of the reaction is presented below:

$\mathrm{R}-\mathrm{COOCH}_{3}+2 \mathrm{H}_{2} \rightarrow \mathrm{R}-\mathrm{CH}_{2} \mathrm{OH}+\mathrm{CH}_{3} \mathrm{OH}$

\subsection{Hydrogenolysis of glycerol}

In the last years, much attention has been devoted to the valorization of glycerol. Glycerol is obtained as byproduct in the transesterification reaction of fatty acids to produce biodiesel. With the significant increase of worldwide biodiesel production, there is also an important increase in glycerol availability. Due to the increments in biodiesel manufacture, important amounts of glycerol have been placed in the market, and glycerol has become a waste difficult to handle. The volumes of glycerol remaining unsold in recent years are a clear example of wasted energy and material resources. This is the reason why intense research activity has started worldwide in order to find an exit to the big amounts of glycerol produced. Glycerol price has experimented constant reduction during the last years. Low glycerol prices allow new interesting applications like the production of high added value chemicals. Effective valorization of glycerol will enable to make more cost effective biodiesel production and to replace fossil fuels as the raw material for the production of commodity chemicals.

Among the different possible transformations of glycerol, the hydrogenolysis to propanediols (PDO) presents special interest due to the big number of applications of both 1,2 and 1,3-propanediol (PDO). 1,3-PDO has traditionally been considered a specialty chemical; it has been used in the synthesis of polymers and other organic chemicals, but its market has been quite small. However, over the past years this situation has changed significantly. 1,3PDO is a starting material in the production of polyesters. It is used together with terephthalic acid to produce polytrimethylene terephthalate (PTT), which is in turn used for the manufacture of fibers and resins. This polymer is currently manufactured by Shell Chemical (Corterra polymers) and DuPont (Sorona 3GT).1,2-PDO is a major commodity chemical traditionally derived from propylene oxide, and hence also based on fossil feedstock. It is a widely used commodity chemical that plays a significant role in the manufacture of a broad array of industrial and consumer products, including unsaturated polyester resins, plasticizers and thermoset plastics, antifreeze products, heat-transfer and coolant fluids, aircraft and runway deicing products, solvents, hydraulic fluids, liquid detergents, paints, lubricants, cosmetics and other personal care products. Today, the industry estimates a global demand for 1,2- PDO between 2.6 and 3.5 billion $\mathrm{lb} / \mathrm{yr}$ [48]. One of the future main markets for 1,2PDO shall be the substitution of ethylene glycol (EG) in cooling water systems to prevent freezing, as ethylene glycol is harmful to health. 


\subsubsection{Reaction mechanisms}

Glycerol hydrogenolysis to PDOs consists of hydrogen addition and removal of one oxygen atom in the form of $\mathrm{H}_{2} \mathrm{O}$. In order to design efficient catalysts, it is fundamental to understand the mechanism of this reaction. Three main reaction mechanisms have been proposed in the literature, depending on whether the reaction runs on acid or basic catalytic sites and with or without the formation of intermediate compounds:

i. dehydrogenation - dehydration - hydrogenation (glyceraldehyde route),

ii. dehydration- hydrogenation,

iii. direct glycerol hydrogenolysis.

Below, the main features of each mechanism will be discussed

i. Glyceraldehyde route

One of the first studies related to glycerol hydrogenolysis was developed by Montassier et al. [40] in the late 1980s. They suggested that over $\mathrm{Ru} / \mathrm{C}$ catalyst glycerol is first dehydrogenated to glyceraldehyde on the metal sites. Next, a dehydroxylation reaction takes place by a nucleophilic reaction of glyceraldehyde with water or with adsorbed -OH species. Finally, hydrogenation of the intermediate yields 1,2-PDO (Figure 9). The main controversial point of this mechanism is the initial dehydrogenation step, which is thermodynamically unfavored due to the high hydrogen pressures used [41]. Therefore, in order to shift the equilibrium, glyceraldehyde dehydration should be faster than glycerol dehydrogenation. Otherwise glyceraldehyde would be hydrogenated back to glycerol on the metal sites. Several authors observed that the addition of a base notably increased glycerol conversion, and this was related to the fact that bases enhance glyceraldehyde dehydration [42-44]. It is interesting to point out that when glycerol hydrogenolysis is carried out under alkaline conditions, marginal 1,3-PDO selectivities are measured.

Apart from 1,2-PDO, other products stemming from C-C bond cleavage were also reported when glycerol hydrogenolysis is conducted under alkaline conditions; mainly, ethylene glycol (EG), methanol and methane. It is suggested that glyceraldehyde can either undergo dehydration or retro-aldolization reactions. The so formed intermediates are hydrogenated in the last step to yield the products of $\mathrm{C}-\mathrm{C}$ bond cleavage. Because both the glyceraldehyde dehydration and glyceraldehyde retro-aldol reaction are catalyzed by $\mathrm{OH}^{-}$, the addition of a base increases the glycerol reaction rate but does not improve the selectivity to 1,2-PDO [45].
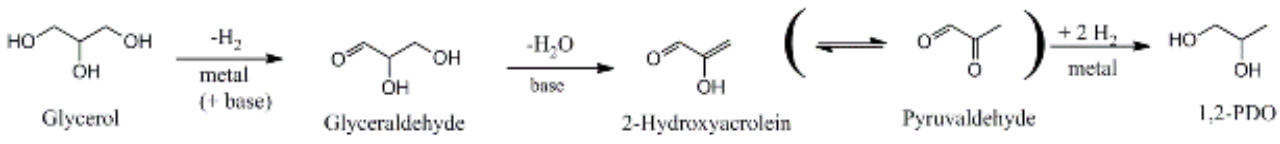

Figure 9. PDO formation from glycerol under alkaline conditions. 
ii. Dehydration-hydrogenation route

Dasari et al. [46] observed the formation of acetol (hydroxyacetone) together with 1,2-PDO using copper-chromite catalyst at $473 \mathrm{~K}$ and 15 bar hydrogen pressure. Moreover, glycerol hydrogenolysis to 1,2-PDO occurred even in the absence of water. Since the copper-chromite catalyst was reduced in a stream of hydrogen prior to the reaction, no surface hydroxyl species were present to take part in the reaction. Therefore, the mechanism suggested by Montassier et al. (Figure 9) was not able to explain these results. Dasari et al. proposed a new mechanism in which glycerol is first dehydrated to acetol, which is further hydrogenated to 1,2-PDO (Figure 10). Based on their findings, a two step process was developed [47]. In the first step, acetol is generated from glycerol dehydration by a reactive distillation process, operating at $513 \mathrm{~K}$, slight vacuum and using copper-chromite catalyst. The acetol obtained is then hydrogenated at 15 bar $\mathrm{H}_{2}$ pressure using the same catalyst. The process was patented in the USA in 2005 [48].

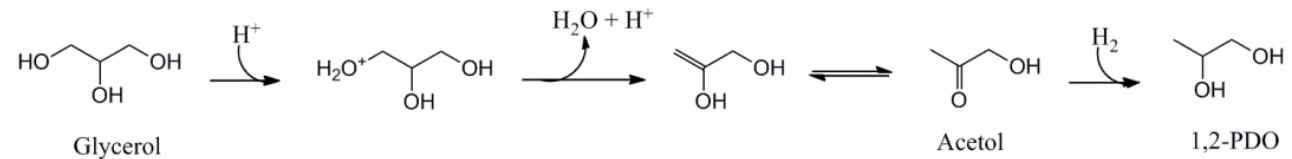

Figure 10. PDO formation via the dehydration-hydrogenation route.

According to Schlaf, acid-catalyzed hydrogenolytic cleavage of -OH group occurs through an initial protonation of the hydroxyl group that leads to the formation of a carbocation and water [49]. Thermodynamically, the formation of a secondary carbocation is more favored than the formation of a primary carbocation. Therefore, operating under acid conditions should bring about higher selectivity to 1,3-PDO. The fact that product distribution is usually shifted towards 1,2-PDO seems to be a complex function of operating conditions, catalyst and starting materials. Ethylene glycol, ethanol, methanol and methane are usually reported as degradation products. Ethylene glycol and methanol are formed from the C-C bond cleavage reaction of glycerol, while ethanol stems from the further hydrogenolysis of ethylene glycol.

iii. Direct glycerol hydrogenolysis

A direct glycerol hydrogenolysis mechanism was recently proposed by Yoshinao et al. [50]. The experiments were carried out using $\mathrm{Rh}-\mathrm{ReO}_{x} / \mathrm{SiO}_{2}$ and $\mathrm{Ir}-\mathrm{ReO}_{x} / \mathrm{SiO}_{2}$ catalysts at $393 \mathrm{~K}$ and 80 bar $\mathrm{H}_{2}$ pressure. The low reaction temperature implies that the dehydration-hydrogenation route was not further possible, due to the endothermic character of glycerol dehydration and the required activation energy, and suggests the energetically more favored direct hydrogenolysis reaction [51]. They suggested a direct hydride ' proton mechanism. The selected catalysts are able to activate hydrogen easily and to form hydride species. It is proposed that glycerol is adsorbed on the surface of $\mathrm{ReO}_{x}$ clusters to form alkoxide species. Glycerol can form two adsorbed alkoxides: 2,3-dihydroxypropoxide and 1,3-dihydroxyiso- 
propoxide; it is suggested that the formation of 2,3-dihydroxypropoxide is preferred as it requires a smaller adsorption cross-section than 1,3-dihydroxyisopropoxide [52]. Next, the hydride attack to the 2-position of 2,3-dihydroxypropoxide gives 1,3-PDO, while the hydride attack to the 3-position of 2,3-dihydroxyisopropoxide yields 1,2-PDO. The higher selectivity to $1,3-\mathrm{PDO}$ obtained $(1,3-\mathrm{PDO} / 1,2-\mathrm{PDO}$ ratio $=2.7)$ is explained on the basis of the higher stability of the six membered-ring transition state that leads to the formation of 1,3PDO as compared to the stability of the seven membered-ring transition state that leads to the formation of 1,2-PDO (Figure 11).

(a) Glycerol hydrogenolysis to 1,3-PDO (b) Glycerol hydrogenolysis to 1,2-PDO
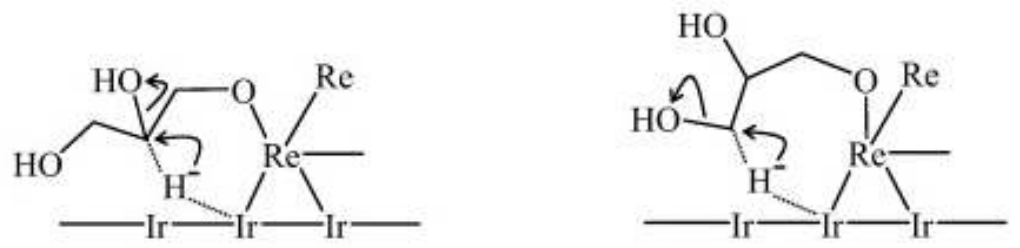

Figure 11. Model structures of the transition states of the hydride attack to the adsorbed substrate in the glycerol hydrogenolysis [52].

A different direct glycerol hydrogenolysis mechanism was established by Chia et al. [53] trying to explain the hydrogenolysis of different polyols and cyclic ethers over a $\mathrm{Rh}-\mathrm{ReO}_{\mathrm{x}} / \mathrm{C}$ catalyst. They concluded from DFT calculations that the -OH groups on Re associated with $\mathrm{Rh}$ are acidic. The acidic nature of $\mathrm{ReO}_{\mathrm{x}}$ was also reported before [54]. Such acidic Re sites can donate a proton to the reactant molecule and form carbenium ion transition states. In the case of glycerol hydrogenolysis, the first step involves the formation of a carbocation by protonation-dehydration reaction. This carbocation is stabilized by the formation of a more stable oxocarbenium ion intermediate resulting from the hydride transfer from the primary $\mathrm{CH}_{2} \mathrm{OH}$ group. Final hydride transfer step leads to 1,2-PDO or 1,3-PDO [53]. The authors also reported that the secondary carbocation is more stable than the primary carbocation. Nevertheless, higher selectivity to 1,2-PDO was obtained (1,3-PDO/1,2-PDO ratio $=0.65)$.

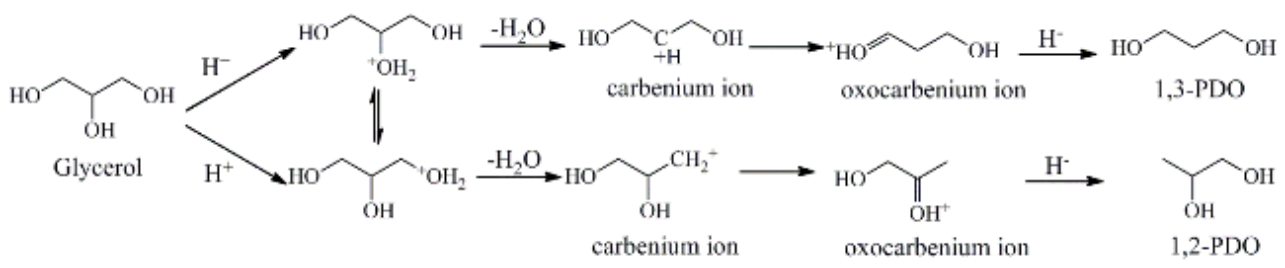

Figure 12. Reaction mechanism for direct glycerol dehydrogenation. Adapted from[55]. 


\subsubsection{Catalytic systems}

i. $\quad$ Noble metals

Hydrogenolysis reactions involve the addition of hydrogen to an organic molecule. Therefore, hydrogenolysis catalysts must be able to activate hydrogen molecules. Noble metals are known to be active for the dissociation of hydrogen molecules and are widely used in hydrogenation reactions. The first studies on glycerol hydrogenolysis were carried out using $\mathrm{Ru}$ based catalysts [56]. Feng et al. [57] studied the effect of different supports $\left(\mathrm{TiO}_{2}, \mathrm{SiO}_{2}\right.$, $\mathrm{NaY}, \gamma-\mathrm{Al}_{2} \mathrm{O}_{3}$ ) on $\mathrm{Ru}$ based catalysts. The $\mathrm{TiO}_{2}$ supported catalyst exhibited the highest activity giving a glycerol conversion of $90.1 \%$; however, it also favored the production of ethylene glycol over 1,2-PDO. In contrast, $\mathrm{Ru} / \mathrm{SiO}_{2}$ showed the lowest activity, but resulted in much higher selectivity to 1,2-PDO. They also performed blank reactions with the supports, achieving no significant conversions; which indicated that the supports cannot catalyze the reaction independently. Ru particle size was affected by the type of support, and a correlation was established between the size of the Ru particle and the activity of the catalyst, being higher with decreasing Ru particle size.

Apart from $\mathrm{Ru}$, other noble metals have also been studied. For instance, Furikado et al. [58] compared the activity of various supported noble-metal catalysts $(\mathrm{Rh}, \mathrm{Ru}, \mathrm{Pt}$ and $\mathrm{Pd}$ over $\mathrm{C}$, $\mathrm{SiO}_{2}$ and $\mathrm{Al}_{2} \mathrm{O}_{3}$ ). Among all the catalysts, the best results in terms of 1,2-PDO selectivity were achieved with $\mathrm{Rh} / \mathrm{SiO}_{2}$ at low reacting temperature and low glycerol conversions (7.2). Nevertheless, the selectivities to 1,2-PDO obtained were rather low, due to the over-hydrogenolysis of 1,2- and 1,3-PDO to 1 and 2-PO.

The use of noble metal-base bifunctional catalytic systems has also been reported. As it was previously described in the glyceraldehyde based mechanism, the dehydration of glycerol to glyceraldehyde, and further dehydration of glyceraldehyde to pyruvaldehyde are both thought to be catalyzed by adsorbed hydroxyls. The effect of different base additives on the performance of $\mathrm{Ru} / \mathrm{TiO}_{2}$ was reported [45]. The addition of $\mathrm{Li}$ or Na hydroxides dramatically increased the glycerol hydrogenolysis activity of $\mathrm{Ru} / \mathrm{TiO}_{2}$ and the selectivity to 1,2-PDO. The highest conversion of glycerol $(89.6 \%)$ and the highest selectivity to 1,2-PDO (86.8\%) were observed with $\mathrm{LiOH}$. The selectivity to 1,2-PDO was similar with all the bases added, which showed that the selectivity to 1,2-PDO is independent of base concentration within a certain range. However, the selectivity to ethylene glycol decreased no matter which base was added. Almost no reaction was observed in the absence of $\mathrm{Ru} / \mathrm{TiO}_{2}$, indicating that the presence of metal is required in order to take place glycerol hydrogenolysis. The lower selectivity to ethylene glycol with increasing base addition to the reacting solution was explained by the fact that ethylene glycol presented higher affinity to adsorb in the surface of the catalyst and to suffer the attack of hydroxyl groups, whose concentration was higher at elevated $\mathrm{pH}$ values [59].

Noble metal-acid catalytic systems have also been used. According to the mechanism in Figure 10, glycerol is firstly dehydrated to acetol, which is then hydrogenated to 1,2-PDO. The first dehydration step is supposed to be catalyzed by acid sites while the second one by metal sites. Therefore, one interesting option to increase the selectivity to target product, 1,2- 
PDO, is the use of bifunctional noble metal-acid catalysts. Different Bronsted acids like sulfonated zirconia, zeolites, homogeneous $\mathrm{H}_{2} \mathrm{SO}_{4}$ and Amberlyst 15 were tested together with $\mathrm{Ru} / \mathrm{C}[60,61]$. Acid-type cation-exchange resin Amberlyst 15 was the most effective cocatalyst. Nevertheless, a weak point in the system of $\mathrm{Ru} / \mathrm{C}$ with Amberlyst 15 is that the reaction temperature is limited to $393 \mathrm{~K}$. At higher temperatures sulfur compounds such as $\mathrm{SO}_{2}$ and $\mathrm{H}_{2} \mathrm{~S}$, which are formed by the thermal decomposition of the sulphonic groups of the resins, poison the catalyst. Using Amberlyst 70 the reacting temperature can be increased to $453 \mathrm{~K}$ before observing thermal decomposition [62].

\begin{tabular}{|c|c|c|c|c|c|c|c|c|}
\hline Catalyst & $\begin{array}{l}\mathrm{H}_{2} \\
\text { (bar) }\end{array}$ & $\begin{array}{l}\text { Temp. } \\
\left({ }^{\circ} \mathrm{C}\right)\end{array}$ & $\begin{array}{l}\text { Glyc. } \\
\text { Conc. } \\
\text { (wt.\%) }\end{array}$ & $\mathrm{mg}_{\mathrm{cat}} / \mathrm{g}_{\mathrm{glyc}}$ & $\begin{array}{l}\text { Time } \\
\text { (h) }\end{array}$ & $\begin{array}{l}\text { Conv. } \\
\text { (\%) }\end{array}$ & $\begin{array}{l}\text { Product Selectivity } \\
(\%)\end{array}$ & Ref \\
\hline $\mathrm{Ru} / \mathrm{TiO}_{2}, 5 \mathrm{wt} \%$ & 50 & 180 & 20 & 96 & 12 & 90.1 & 1,2-PDO (21), EG (41) & [57] \\
\hline $\begin{array}{l}\mathrm{Pt} / \mathrm{C}, 3 \mathrm{wt} \% \\
+\mathrm{CaO} 0.8 \mathrm{M}\end{array}$ & 40 & 200 & 1 & 233 & 5 & 40 & $\begin{array}{l}\text { 1,2-PDO (71), lacticacid (19), } \\
\text { EG (9) }\end{array}$ & , [42] \\
\hline $\begin{array}{l}\text { Ru/C, } 5 w t \% \\
+ \text { Amberlyst } 15\end{array}$ & 80 & 120 & 20 & 112.5 & 10 & 79.3 & $\begin{array}{l}\text { 1,2-PDO (75), 1-PO(8), 2-PO } \\
\text { (2), EG (7) }\end{array}$ & [63] \\
\hline $\begin{array}{l}\text { Ru/C, 5wt\% } \\
+ \text { Amberlyst } 70\end{array}$ & 80 & 180 & 20 & 12.2 & 10 & 48.8 & $\begin{array}{l}\text { 1,2-PDO (70), 1,3-PDO (1.3), } \\
\text { 1-PO (7.1), EG (8.3) }\end{array}$ & [62] \\
\hline $\mathrm{Cu} / \mathrm{Al}_{2} \mathrm{O}_{3}, 60 w t \%$ & 1 & $120-200$ & 30 & - & $0.066 \mathrm{~h}^{-1 \mathrm{a}}$ & 100 & 1,2-PDO (96.9), acetol (1.4) & [64] \\
\hline $\mathrm{Cu} / \mathrm{SiO}_{2}, 30 \mathrm{wt} \%$ & 90 & 180 & 80 & 62.5 & 12 & 32.7 & 1,2.PDO (98), EG (1) & [65] \\
\hline $\begin{array}{l}\mathrm{Cu}_{0.4} / \mathrm{Mg}_{5.6} \mathrm{Al}_{2} \mathrm{O}_{9} \\
+\mathrm{NaOH}\end{array}$ & 30 & 180 & 75 & 166 & 20 & 91 & 1,2-PDO (96), EG (3) & [44] \\
\hline $\mathrm{Pd}_{0.04} \mathrm{Cu}_{0.4} \mathrm{Mg}_{5.6-} \mathrm{Al}_{2}(\mathrm{OH})$ & 20 & 180 & 75 & 166 & 10 & 77 & 1,2-PDO (98), EG (1.6) & [66] \\
\hline $\begin{array}{l}\mathrm{Ir}-\mathrm{ReO}_{x} / \mathrm{SiO}_{2}, 4 \mathrm{wt} \% \\
(\mathrm{Re} / \mathrm{Ir}=1)\end{array}$ & 80 & 120 & 20 & 37.5 & 36 & 81.0 & $\begin{array}{l}\text { 1,2-PDO (4.2), 1,3-PDO } \\
(46.3), 1-P O(41.2)\end{array}$ & [72] \\
\hline
\end{tabular}

a WHSV (weight hour space velocity)

Table 2. Selected examples of hydrogenolysis of aqueous glycerol over heterogeneous catalysts. PDO: Propanediol, PO: Propanol, EG: Ethylene Glycol.

The use of more stable inorganic salts can avoid the temperature problems related to ionexchange resins. Balaraju et al. [67] used the combination of $\mathrm{Ru} / \mathrm{C}$ catalyst with different inorganic salts such as niobia, zirconia-supported 12-tungstophosphoric acid or acid caesium 12-tungstophosphate in glycerol hydrogenolysis at $453 \mathrm{~K}$. The best results were achieved with those co-catalysts presenting a high number of medium strength acid sites. Particularly, with niobia as co-catalyst $62.8 \%$ glycerol conversion and $66.5 \%$ 1,2-PDO selectivity were reported. Another option is the use of a noble metal on acid supports. Vasiliadou et al. [68] investigated glycerol hydrogenolysis on Ru-based $\left(\gamma-\mathrm{Al}_{2} \mathrm{O}_{3}, \mathrm{SiO}_{2}, \mathrm{ZrO}_{2}\right)$ catalysts at $513 \mathrm{~K}$ and 80 bar. The nature of the oxidic support was found to influence the ability of the catalyst to both activate the glycerol substrate and selectively convert it to propanediol. The characterization of the catalytic materials revealed a correlation between catalytic activity for the 
hydrogenolysis reaction and total acidity, as the yield to hydrogenolysis products increased with the concentration of the acid sites. However, increased acidity was also responsible for the promotion of the excessive hydrogenolysis of the desired 1,2-propanediol to propanols.

ii. $\quad$ Cu based catalysts

$\mathrm{Cu}$ has been extensively investigated in the glycerol hydrogenolysis reactions. Although its hydrogenation activity is generally lower than that of noble metals, its much lower price and its ability to catalyze $\mathrm{C}-\mathrm{O}$ bond but not $\mathrm{C}-\mathrm{C}$ bond hydrogenolysis make $\mathrm{Cu}$ catalysts attractive for this process. There are some works in the literature that report the use of other transition metals like $\mathrm{Ni}$ or $\mathrm{Co}$, however, $\mathrm{Cu}$ based catalysts are predominant. Vapor phase glycerol dehydration reaction was studied by Sato et al. [69] over different copper catalysts at $513 \mathrm{~K}$ and atmospheric $\mathrm{N}_{2}$ pressure. They observed that basic $\mathrm{MgO}, \mathrm{CeO}_{2}$, and $\mathrm{ZnO}$ supports showed low acetol selectivity, while acidic supports, such as $\mathrm{Al}_{2} \mathrm{O}_{3}, \mathrm{ZrO}_{2}, \mathrm{Fe}_{2} \mathrm{O}_{3}$, and $\mathrm{SiO}_{2}$, effectively promoted acetol formation. The best results were obtained with $\mathrm{Cu} / \mathrm{Al}_{2} \mathrm{O}_{3}$ catalyst. Increments in copper content lead to increments in acetol selectivity. Moreover, the activity of the $\mathrm{Al}_{2} \mathrm{O}_{3}$ support alone was rather low, which indicates that copper metal sites play a significant role in glycerol dehydration. Continuing with vapor phase processes, Akiyama et al. [64,70] studied glycerol hydrogenolysis in a fixed-bed down-flow glass reactor at temperatures between 340 and $473 \mathrm{~K}$, atmospheric hydrogen pressure, and using $\mathrm{Cu} / \mathrm{Al}_{2} \mathrm{O}_{3}$ catalysts. In the two step reaction they observed that glycerol dehydration to acetol was favored at relatively high temperatures. However, acetol hydrogenation to 1,2-PDO was favored at lower temperatures, because it is an exothermic reaction and the dehydrogenation of 1,2-PDO occurs preferentially at high temperatures. Based on these findings, they developed a reactor with gradient temperatures, at the top of the reactor glycerol dehydration reaction occurred at $453 \mathrm{~K}$ while at the bottom of the reactor acetol was hydrogenated to 1,2-PDO at $418 \mathrm{~K}$. Really high 1,2-PDO yields (94.9\%) were reported.

Some of the best results in terms of glycerol conversion and 1,2-PDO selectivity were recently reported using $\mathrm{Cu}$ on base supports. For instance, Yuan et al. [44] developed a $\mathrm{Cu}$ based solid catalyst $\left(\mathrm{Cu}_{0.4} / \mathrm{Mg}_{5.6} \mathrm{Al}_{2} \mathrm{O}_{8.6}\right)$ via thermal decomposition of the as-synthesized $\mathrm{Cu}_{0.4} \mathrm{Mg}_{5.6} \mathrm{Al}_{2}(\mathrm{OH})_{16} \mathrm{CO}_{3}$ layered double hydroxides. This bifunctional highly dispersed $\mathrm{Cu}-$ solid base catalyst was effective for hydrogenolysis of aqueous glycerol. The measured conversion of glycerol reached $80.0 \%$ with a $98.2 \%$ selectivity of 1,2 -propanediol at $180{ }^{\circ} \mathrm{C}, 30$ bar $\mathrm{H}_{2}$ and $20 \mathrm{~h}$. The addition of $\mathrm{Pd}$ to the same catalytic system notably increased the activity of the catalyst [71]. It was suggested that the hydrogen spill over from $\mathrm{Pd}$ to $\mathrm{Cu}$ favored glycerol hydrogenolysis to 1,2-PDO.

iii. Metal oxide modified-noble metal

As stated above, the use of acid or base as a co-catalyst gives 1,2-PDO as a main product. To obtain more valuable 1,3-PDO, the most effective approach has shown to be the use of noble metal ( $\mathrm{Ir}$, Rh or Pt) combined with oxophilic metals. Shinmi et al. [52] modified $\mathrm{Rh} / \mathrm{SiO}_{2}$ catalyst with Re, W and Mo. Re addition showed the largest enhancing effect on catalytic activity and also increased the selectivity to 1,3-PDO. The $\mathrm{Rh}-\mathrm{ReOx} / \mathrm{SiO}_{2}(\mathrm{Re} / \mathrm{Rh}=0.5)$ exhibited 22 times higher glycerol conversion (79\%) and 37 times higher 1,3-PD yield (11\%) than 
$\mathrm{Rh} / \mathrm{SiO}_{2}$. In a more recent work, an $\mathrm{Ir}-\mathrm{ReO}_{x} / \mathrm{SiO}_{2}(\mathrm{Re} / \mathrm{Ir}=1)$ catalyst prepared by a similar method to that for $\mathrm{Rh}-\mathrm{ReO}_{x} / \mathrm{SiO}_{2}$, catalyzed the hydrogenolysis of glycerol to 1,3-PDO in a more effectively way $(1,3-\mathrm{PDO} / 1,2-\mathrm{PDO}$ ratio $=11)$ [72]. Based on characterization results, the authors suggested that oxidized low-valence Re clusters are attached to the Ir or Rh metal particles. Glycerol is adsorbed on the surface of $\mathrm{MO}_{x}$ species $(\mathrm{M}=\mathrm{Mo}$, Re and $\mathrm{W})$ at the $\mathrm{OH}$ group to form alkoxide. Hydrogen is activated on the noble-metal (Rh or Ir) surface. The alkoxide located on the interface between $\mathrm{MO}_{x}$ and the noble-metal surface is attacked by the activated hydrogen species, and the $\mathrm{C}-\mathrm{O}$ bond neighboring to the $\mathrm{C}-\mathrm{O}-\mathrm{M}$ group is dissociated. The hydrolysis of the resulting alkoxide releases the product (see Figure 11). One of the weak point of these catalytic systems is that they are also active in the further hydrogenolysis of both 1,2 and 1,3-PDO to 1-PO.

In summary, $\mathrm{Cu}$ based catalysts are active and selective for the production of 1,2-PDO from glycerol. However, if the aim is to produce the more valuable 1,3-PDO, different approaches are required. The used of noble metals combined with low-valence metal oxide seems to be a promising alternative. Nonetheless, there is still room for improvement; both in catalyst design and in process engineering, as PDOs further hydrogenolysis significantly affect the final yields to target products.

\section{Main alternatives to the use of molecular hydrogen}

In the previous sections the significance that hydrogenolysis reactions have and will have in the future bio-refineries has been highlighted. In fact, they will be essential in fuel and chemical manufacturing. Hydrogenolysis involves chemical bond dissociation in an organic substrate and simultaneous addition of hydrogen. Therefore, hydrogen is required as reactant in all hydrogenolysis reactions. This is the reason why, most of the literature works referred to hydrogenolysis report experiments conducted under molecular hydrogen $\left(\mathrm{H}_{2}\right)$ atmosphere. Nevertheless, the use of molecular hydrogen has some important drawbacks:

i. Liquid phase processes are preferred to gas phase processes as they are more energy efficient. However, $\mathrm{H}_{2}$ presents really low solubility on aqueous or organic solutions. As a consequence, when operating in liquid phase it is necessary to operate at elevated hydrogen pressures to obtain significant hydrogen concentrations near the catalysts. This, on one hand, notably increases the cost of design and building of the future plants, and on the other hand, increases the operating cost related to safety measures, as hydrogen is easily ignited and shows high diffusivity.

ii. Most of the nowadays available hydrogen gas is produced from fossil fuels by energy intensive processes. Therefore, if sustainability is the goal it is a contradiction that the main reactant in most of the biorefinery processes is based on fossil resources.

iii. The low density and high diffusivity of hydrogen make problematic and expensive its transportation and storage. This problem is more relevant for small size biomass conversion facilities. 
Hydrogen from non fossil origin will surely be a reality in the oncoming years, as reforming processes from various renewable compounds (like biomethane, glycerol or ethanol) and water splitting processes using solar light are being intensively developed. Nonetheless, the problems of transportation, storage and low solubility in liquid solutions will remain. One interesting option that could solve the problems associated to the use of molecular hydrogen is to directly generate the required hydrogen in the active sites of the catalyst.

\subsection{Bio-oil upgrading using hydrogen donating solvents}

One interesting approach to reduce the consumption of molecular hydrogen during the $\mathrm{HDO}$ of bio-oils is to use hydrogen donating solvents. For instance, Elliott has reported that when the bio-oil upgrading is carried out in the presence of a hydrogen donor solvent (tetralin, 1-1 ratio with bio-oil feedstock) the oxygen removal increases from 70 to $85 \%$ and less deactivation of the catalyst was observed. Some of the components already present in the bio-oil, such as alcohols or acids, may also provide hydrogen for the deoxygenation reactions [10]. Traditional catalysts active in hydrogen transfer reactions, such as $\mathrm{Pd}, \mathrm{Ni}$ or $\mathrm{Cu}$ should be used in this process [73].

Another attractive option is to use hydrogen donating solvents during the hydrotreating of biomass. The idea is to obtain a bio-oil with a lower oxygen content, and therefore, easier to upgrade. This concept has been mainly applied in the pyrolysis of lignin. If a hydrogen donor molecule is added during the pyrolysis, both depolymerization and hydrogenation occur simultaneously. Remarkable results have been obtained using hydrogen-donating solvents, such as tetralin or 9,10-dihydroanthracene [74]. However, a major drawback is the need for large quantities of these solvents. At this point, formic acid appears to be a promising donor molecule, as it can be obtained together with levulinic acid from the hydrolysis of biomass. On heating, formic acid decomposes completely into $\mathrm{CO}_{2}$ and two active hydrogen atoms, which are efficient scavengers of any radical species formed in the lignin. By successive homolytic cleavage of the covalent linkages of the lignin, including aromatic rings, most of the oxygen is removed as water and hydrocarbons are formed (Figure 13). When pyrolysis is carried out with formic acid, lignin can be converted into hydrogen-rich, oxygen depleted products with no added catalyst [75].

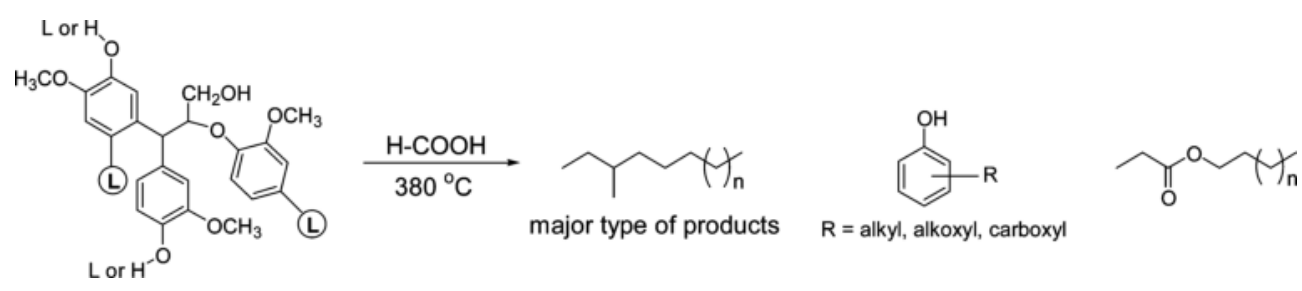

Figure 13. Schematic picture of the products formed upon the pyrolysis of lignin in thepresence of formic acid [75]. 


\subsection{Hydrogenolysis with in-situ generation of hydrogen}

\subsubsection{Aqueous Phase Reforming (APR)}

One interesting option to in situ generate the required hydrogen for hydrogenolysis reactions is through aqueous phase reforming (APR). APR is a quite well known process in which a polyol is converted to hydrogen and $\mathrm{CO}_{2}$ in the presence of water. The hydrogen generated can be further used in the hydrogenolysis reaction. The specific case for combined glycerol APR and hydrogenolysis to 1,2-PDO is shown in Figure 14. If the process is perfectly balanced, glycerol is fully converted into 1,2-PDO, being $\mathrm{CO}_{2}$ and $\mathrm{H}_{2} \mathrm{O}$ the only byproduct. Tailored metal-acid bifunctional catalysts or combination of catalysts are required to obtain high yields to 1,2-PDO. Indeed, there must be a proper balance between the C-C bond cleavage reactions that lead to the production of hydrogen, and the $\mathrm{C}-\mathrm{O}$ bond cleavage reactions that lead to the formation of PDOs [76]. While $\mathrm{Pt}$ is known to be active in $\mathrm{C}-\mathrm{C}$ bond cleavage, its combination with other metals active in $\mathrm{C}-\mathrm{O}$ bond hydrogenolysis, like $\mathrm{Ni}$, Sn or $\mathrm{Ru}$, over acidic supports appears as promising formulations to obtain high yields to 1,2-PDO [77]. However, glycerol APR itself runs at elevated pressure and therefore the advantage over conventional hydrogenolysis at high hydrogen pressure is marginal with regard to equipment and safety costs.

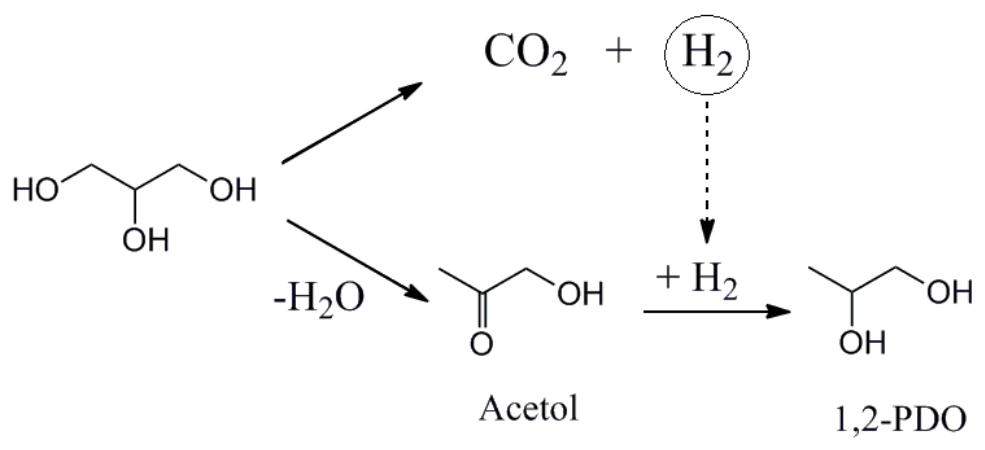

Figure 14. Combined glycerol APR and hydrogenolysis to 1,2-PDO.

The same benefits that have been previously addressed for the use of in situ generated hydrogen in glycerol hydrogenolysis can be applied to the conversion of other higher polyols, like sorbitol or xylitol. However, the considerable research effort that has been directed to the conversion of glycerol yet has not been paid to other biomass based polyols. Therefore, the amount of works related to high polyol hydrogenolysis with in situ generation of the required hydrogen is quite scarce. As a consequence of this, it is a really interesting and open research field. 
Huber et al. [78] studied the production of renewable alkanes (C1-C6) from the aqueous phase reforming of sorbitol using a $\mathrm{Pt} / \mathrm{SiO}_{2}-\mathrm{Al}_{2} \mathrm{O}_{3}$ catalyst.They suggested a multistep bifunctional reaction pathway. The first step involves the formation of $\mathrm{CO}_{2}$ and $\mathrm{H}_{2}$ on the $\mathrm{Pt}$ sites, and the dehydration of sorbitol on the acid sites of the silica-alumina support. These initial steps are followed by hydrogenation of the dehydrated reaction intermediates on the metal catalyst (Scheme 9). $64 \%$ alkane selectivity at 92\% sorbitol conversion were recorded at 498 $\mathrm{K}$ and 39.6 bar. When hydrogen was co-fed, alkane selectivity significantly increased up to $91 \%$. Glucose showed to be less active than sorbitol over a $\mathrm{Pt} / \mathrm{Al}_{2} \mathrm{O}_{3}$ catalyst at $538 \mathrm{~K}$ and 52.4 bar of $\mathrm{N}_{2}$ pressure, achieving moderate alkane selectivities (49.5\%) [79]. Therefore, it seems that initial hydrogenation of glucose to sorbitol and subsequent aqueous phase reforming of the sugar is more effective than direct aqueous phase reforming of glucose.

\subsubsection{Catalytic Transfer Hydrogenation}

Catalytic transfer hydrogenation $(\mathrm{CTH})$ is a process in which hydrogen is transferred from a hydrogen donor molecule to an acceptor [80]. CTH reactions can be of industrial importance as the renewable production, transportation and storage of hydrogen donors can be cheaper than those for molecular hydrogen. For CTH, it has been reported that adjacent sites may be necessary for donor and acceptor molecules [73]. Therefore, the first criterion to be fulfilled by the selected hydrogen donor molecules is to be soluble in the compound to be hydrotreated. Moreover, in order to improve the yield of desired products, reactions other than dehydrogenation of the donor should be minimized under the operating conditions. The best hydrogen donors for heterogeneous CTH include simple molecules like cyclohexene, hydrazine, formic acid and formates [81]. Alcohols like 2-propanol (2-PO) or methanol can also be used as hydrogen donors; primary alcohols are generally less active than the corresponding secondary alcohols due to the smaller electron-releasing inductive effect of one alkyl group as against two [82]. The most active catalysts for heterogeneous transfer reduction are based on palladium metal. Other noble metals such as Pt and Rh are also widely utilized. Sometimes, other transition metals such as $\mathrm{Ni}$ and $\mathrm{Cu}$ have also been reported but for operation at higher temperature [73].

In this area, the most studied process has been the conversion of glycerol into 1,2-PDO. Musolino et al. [83] studied glycerol hydrogenolysis by transfer hydrogenation under 5 bar inert atmosphere, using ethanol and 2-PO as solvents and hydrogen donor molecules over $10 \mathrm{PdFe}_{2} \mathrm{O}_{3}$ catalyst at $453 \mathrm{~K}$. They observed that complete glycerol conversion and high selectivities to 1,2-PDO could be obtained when the hydrogen came from the dehydrogenation of the solvent. Formic acid has also been used as a hydrogen donor molecule in the glycerol hydrogenolysis process using $\mathrm{Ni}-\mathrm{Cu} / \mathrm{Al}_{2} \mathrm{O}_{3}$ catalysts [84]. Under the operating conditions used, formic acid was readily converted into $\mathrm{CO}_{2}$ and $\mathrm{H}_{2}$, therefore, a semi-continuous setup was used to continuously pump formic acid to the glycerol water solution, in order to ensure a constant supply of hydrogen at an appropriate rate [85]. For a constant metal content of $35 \mathrm{wt}-\%(\mathrm{Ni}+\mathrm{Cu})$, increasing $\mathrm{Ni}$ proportion caused an increase in glycerol conversion but also an increase in $\mathrm{C}-\mathrm{C}$ bond cleavage reactions. $\mathrm{Cu}$ is known to be active in the $\mathrm{C}-\mathrm{O}$ bond cleavage but not in the $\mathrm{C}-\mathrm{C}$ bond cleavage. The presence of $\mathrm{Cu}$ and the creation of a 
Ni-Cu alloy notably reduced formation of products $<\mathrm{C}_{3}$. This was related to the fact that $\mathrm{C}-\mathrm{C}$ bond cleavage reactions are ensemble size sensitive and that the formation of a $\mathrm{Cu}-\mathrm{Ni}$ alloy causes a decrease in the Ni ensemble size. Therefore, the presence of both metals is required for obtaining high 1,2-PDO yields: $\mathrm{Ni}$ to provide high hydrogenolysis activity and $\mathrm{Cu}$ to shift the selectivity towards C-O bond cleavage. It was also observed that above a certain metal content, further increments led to a decrease in glycerol conversion. This was correlated to the total acidity of the catalyst that also decreased with increasing metal content. A direct glycerol hydrogenolysis mechanism was also proposed (Figure 15).

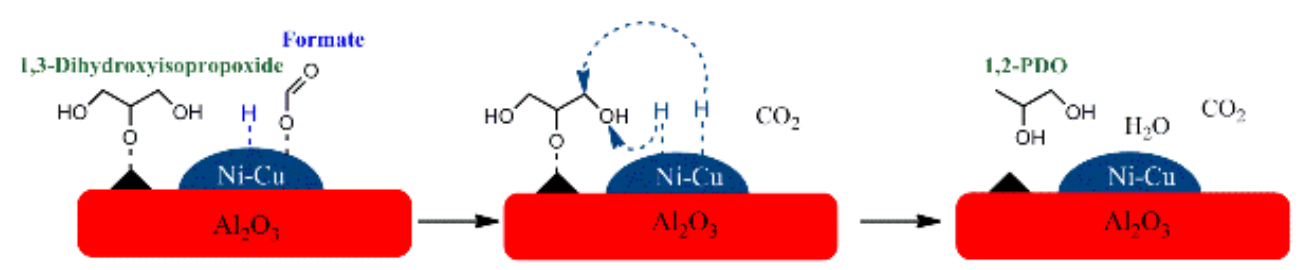

Figure 15. Proposed mechanism for glycerol hydrogenolysis by CTH using formic acid as hydrogen donor molecule [84].

\section{Conclusions}

Bio-oils coming from the pyrolysis of biomass feedstocks and biomass based platform chemicals present a common limiting feature: their high oxygen content. This oxygen can be removed by catalytic hydrotreating in the form of $\mathrm{H}_{2} \mathrm{O}$. Intensive research is required in this field in order to develop catalytic systems active and stable under the hard operating conditions used: high temperatures and pressures, and high concentrations of sub-critical water. The required bifunctional catalysts must have Brönsted acidity to catalyze dehydration reactions or/and Lewis acid sites to attract the oxygen ion pair of the target molecule; but also metal sites that show the ability to activate hydrogen molecules. In this sense, the combination of oxophilic metals ( $\mathrm{Re}, \mathrm{Mo}$ or $\mathrm{W}$ ) with Ni or noble metals has shown to be a promising approach. In the case of bio-oil upgrading, the developed catalysts should promote hydrodeoxygenation reactions against hydrogenation reactions that lead to higher hydrogen consumption and reduction in the octane number of the oil. In order to avoid coke formation under the hard operating conditions used, neutral supports appear as an interesting option. In the case of catalysts for platform chemical valorization, C-C bond cleavage reactions should be avoided. Therefore, for some applications, like glycerol hydrogenolysis to 1,2$\mathrm{PDO}, \mathrm{Cu}$ based catalysts have to be considered due to the high selectivity of $\mathrm{Cu}$ for $\mathrm{C}-\mathrm{O}$ bond cleavage reactions.

Hydrogenolysis processes for oxygen removal require the use of large amounts of hydrogen, which is commonly supply by operating under high molecular hydrogen pressures. Nonetheless, this might be a problem because nowadays, most technologies to obtain hydrogen are energy intensive and non-renewable. An interesting alternative might be to in-situ 
generate the required hydrogen. Among all the alternatives, the use of hydrogen donor molecules that can be obtained from biomass in a renewable way, such as formic acid, appears as a promising approach.

\section{Author details}

Iñaki Gandarias* and Pedro Luis Arias

*Address all correspondence to: inaki_gandarias@ehu.es

Department of Chemical and Environmental Engineering, University of the Basque Country (UPV/EHU) Alameda Urquijo s/n, Bilbao, Spain

\section{References}

[1] USA Energy Information Administration (EIA): International Energy Outlook. http:// www.eia.gov/forecasts/ieo/index.cfm (accessed 08 August 2012).

[2] Bull TE. Biomass in the Energy Picture. Science 1999; 285 (5431) 1209-1209.

[3] Ragauskas AJ, Williams CK, Davison BH, Britovsek G, Cairney J, Eckert CA, Frederick WJ, Hallett JP, Leak DJ, Liotta CL, Mielenz JR, Murphy R, Templer R, Tschaplinski T. The Path Forward for Biofuels and Biomaterials. Science 2006; 311 (5760) 484-489.

[4] Carlos RM, Ba Khang D. Characterization of biomass energy projects in Southeast Asia. Biomass and Bioenergy 2008; 32 (6) 525-532.

[5] Sarkar N, Ghosh SK, Bannerjee S, Aikat K. Bioethanol production from agricultural wastes: An overview. Renewable Energy 2012; 37 (1) 19-27.

[6] Mohan D, Pittman CU, Steele PH. Pyrolysis of Wood/Biomass for Bio-oil: A Critical Review. Energy Fuels 2006; 20 (3) 848-889.

[7] Venderbosch R, Prins W. Fast pyrolysis technology development. Biofuels, Bioproducts and Biorefining 2010; 4 (2) 178-208.

[8] Banu M, Sivasanker S, Sankaranarayanan TM, Venuvanalingam P. Hydrogenolysis of sorbitol over Ni and Pt loaded on NaY. Catalysis Communications 2011; 12 (7) 673-677.

[9] Yusuf NNAN, Kamarudin SK, Yaakub Z. Overview on the current trends in biodiesel production. Energy Conversion and Management 2011; 52 (7) 2741-2751.

[10] Bulushev DA, Ross JRH. Catalysis for conversion of biomass to fuels via pyrolysis and gasification: A review. Catalysis Today 2011; 171 (1) 1-13. 
[11] International Energy Agency. IEA: Sustainable Production of SECOND -Generation Biofuels.http://www.iea.org/papers/2010/second_generation_biofuels.pdf(accessed 25 July 2012).

[12] Bobleter O. Hydrothermal degradation of polymers derived from plants. Progress in Polymer Science 1994; 19 (5) 797-841.

[13] Huber,G.W., Iborra,S., Corma,A. Synthesis of Transportation Fuels from Biomass: Chemistry, Catalysts, and Engineering. Chemical Reviews. 2006; 106 (9) 4044-4098.

[14] Bridgwater AV. Review of fast pyrolysis of biomass and product upgrading. Biomass and Bioenergy 2012; 38 (1) 68-94.

[15] Mortensen PM, Grunwaldt J-, Jensen PA, Knudsen KG, Jensen AD. A review of catalytic upgrading of bio-oil to engine fuels. Applied Catalysis A: General 2011; 407 (12) $1-19$.

[16] Piskorz J., Scott DS.,Radlien D. Composition of oils obtained by fast pyrolysis of different woods. In: Pyrolysis Oils from Biomass: Producing Analyzing and Upgrading. Washington, DC: American Chemical Society; 1988.

[17] Elliott DC. Historical Developments in Hydroprocessing Bio-oils. Energy Fuels 2007; 21 (3) 1792-1815.

[18] Romero Y, Richard F, Brunet S. Hydrodeoxygenation of 2-ethylphenol as a model compound of bio-crude over sulfided Mo-based catalysts: Promoting effect and reaction mechanism. Applied Catalysis B: Environmental 2010; 98 (3-4) 213-223.

[19] Ba T, Chaala A, Garcia-Perez M, Roy C. Colloidal Properties of Bio-Oils Obtained by Vacuum Pyrolysis of Softwood Bark. Storage Stability. Energy Fuels 2004; 18 (1) 188-201.

[20] Şenol Oİ, Viljava T-, Krause AOI. Effect of sulphiding agents on the hydrodeoxygenation of aliphatic esters on sulphided catalysts. Applied Catalysis A: General 2007; 326 (2) 236-244.

[21] Gandarias I, Barrio VL, Requies J, Arias PL, Cambra JF, Güemez MB. From biomass to fuels: Hydrotreating of oxygenated compounds. International Journal of Hydrogen Energy 2008; 33 (13) 3485-3488.

[22] Şenol Oİ, Ryymin E-, Viljava T-, Krause AOI. Reactions of methyl heptanoatehydrodeoxygenation on sulphided catalysts. Journal of Molecular Catalysis A: Chemical 2007; 268 (1-2) 1-8.

[23] Ravenelle RM, Copeland JR, Kim W, Crittenden JC, Sievers C. Structural Changes of $\hat{\mathrm{I}}^{3}$-Al2O3-Supported Catalysts in Hot Liquid Water. ACS Catalysis 2011; 1 (5) 552-561.

[24] Centeno A, Laurent E, Delmon B. Influence of the Support of CoMo Sulfide Catalysts and of the Addition of Potassium and Platinum on the Catalytic Performances for the Hydrodeoxygenation of Carbonyl, Carboxyl, and Guaiacol-Type Molecules. Journal of Catalysis 1995; 154 (2) 288-298. 
[25] Echeandia S, Arias PL, Barrio VL, Pawelec B, Fierro JLG. Synergy effect in the HDO of phenol over $\mathrm{Ni}-\mathrm{W}$ catalysts supported on active carbon: Effect of tungsten precursors. Applied Catalysis B: Environmental 2010; 101 (1-2) 1-12.

[26] Gutierrez A, Kaila RK, Honkela ML, Slioor R, Krause AOI. Hydrodeoxygenation of guaiacol on noble metal catalysts. Catalysis Today 2009; 147 (3-4) 239-246.

[27] Venderbosch RH, Ardiyanti AR, Wildschut J, Oasmaa A, Heeres HJ. Stabilization of biomass-derived pyrolysis oils. Journal of Chemical Technology \& Biotechnology 2010; 85 (5) 674-686.

[28] Bridgwater AV. Production of high grade fuels and chemicals from catalytic pyrolysis of biomass. Catalysis Today 1996; 29 (1-4) 285-295.

[29] Gallezot P, Nicolaus N, Flèche G, Fuertes P, Perrard A. Glucose Hydrogenation on Ruthenium Catalysts in a Trickle-Bed Reactor. Journal of Catalysis 1998; 180 (1) 51-55.

[30] Yadav M, Mishra DK, Hwang J. Catalytic hydrogenation of xylose to xylitol using ruthenium catalyst on $\mathrm{NiO}$ modified $\mathrm{TiO}_{2}$ support. Applied Catalysis A: General 2012; 425-426 (1) 110-116.

[31] Ye L, Duan X, Lin H, Yuan Y. Improved performance of magnetically recoverable Ce-promoted $\mathrm{Ni} / \mathrm{Al} 2 \mathrm{O} 3$ catalysts for aqueous-phase hydrogenolysis of sorbitol to glycols. Catalysis Today 2012; 183 (1) 65-71.

[32] Zhao L, Zhou JH, Sui ZJ, Zhou XG. Hydrogenolysis of sorbitol to glycols over carbon nanofiber supported ruthenium catalyst. Chemical Engineering Science 2010; 65 (1) 30-35.

[33] Nikolla E, RomaÌn-Leshkov Y, Moliner M, Davis ME. One-Pot Synthesis of 5-(Hydroxymethyl)furfural from Carbohydrates using Tin-Beta Zeolite. ACS Catalysis 2011; 1 (4) 408-410.

[34] Roman-Leshkov Y, Barrett CJ, Liu ZY, Dumesic JA. Production of dimethylfuran for liquid fuels from biomass-derived carbohydrates. Nature 2007; 447 (7147) 982-985.

[35] Luijkx GCA, Huck NPM, van Rantwijk F, Maat L, van Bekkum H. Ether Formation in the Hydrogenolysis of Hydroxymethylfurfural over Palladium Catalysts in Alcoholic Solution. ChemInform 2009; 40 (28).

[36] Tong X, Ma Y, Li Y. Biomass into chemicals: Conversion of sugars to furan derivatives by catalytic processes. Applied Catalysis A: General 2010; 385 (1-2) 1-13.

[37] Huber GW, O'Connor P, Corma A. Processing biomass in conventional oil refineries: Production of high quality diesel by hydrotreating vegetable oils in heavy vacuum oil mixtures. Applied Catalysis A: General 2007; 329 (1) 120-129.

[38] Rovetto LJ, Bottini SB, Brignole EA, Peters CJ. Supercritical hydrogenolysis of fatty acid methyl esters: Phase equilibrium measurements on selected binary and ternary systems. The Journal of Supercritical Fluids 2005; 35 (3) 182-196. 
[39] Veldsink JW, Bouma MJ, Schöön NH, Beenackers AACM. Heterogeneous Hydrogenation of Vegetable Oils: A Literature Review. Catalysis Reviews 1997; 39 (3) 253-318.

[40] Montassier C, Ménézo JC, Moukol J, Naja J, Hoang LC, Barbier J. Polyol conversions into furanic derivates on bimetallic catalysts: $\mathrm{Cu}-\mathrm{Ru}, \mathrm{Cu}-\mathrm{Pt}$ and $\mathrm{Ru}-\mathrm{Cu}$. Journal of Molecular Catalysis 1991; 70 65-84.

[41] Ruppert AM, Weinberg K, Palkovits R. Hydrogenolysis Goes Bio: From Carbohydrates and Sugar Alcohols to Platform Chemicals. AngewandteChemie International Edition 2012; 51 (11) 2513-2513.

[42] Maris EP, Davis RJ. Hydrogenolysis of glycerol over carbon-supported $\mathrm{Ru}$ and $\mathrm{Pt}$ catalysts. Journal of Catalalysis 2007; 249 (2) 328-337.

[43] Lahr DG, Shanks BH. Effect of sulfur and temperature on ruthenium-catalyzed glycerol hydrogenolysis to glycols. Journal of Catalysis 2005; 232 (2) 386-394.

[44] Yuan Z, Wang L, Wang J, Xia S, Chen P, Hou Z, Zheng X. Hydrogenolysis of glycerol over homogenously dispersed copper on solid base catalysts. Applied Catalysis B: Environmental 2011; 101 (3-4) 431-440.

[45] Feng J, Wang J, Zhou Y, Fu H, Chen H, Li X. Effect of Base Additives on the Selective Hydrogenolysis of Glycerol over $\mathrm{Ru} / \mathrm{TiO}_{2}$ Catalyst. Chemistry Letters 2007; 36 1274-1275.

[46] Dasari MA, Kiatsimkul P, Sutterlin WR, Suppes GJ. Low-pressure hydrogenolysis of glycerol to propylene glycol. Applied Catalysis A: General 2005; 281 (1-2) 225-231.

[47] Chuang-Wei C, Dasari MA, Suppes GJ. Dehydration of Glycerol to Acetol via Catalytic Reactive Distillation. AICHE Journal 2006; 52 3543-3548.

[48] Suppes,G.J., Sutterling,W.R., Dasari,M.A., 2005; WO2005095536.

[49] Schlaf M. Selective deoxygenation of sugar polyols to $\alpha, \omega$-diols and other oxygen content reduced materials-a new challenge to homogeneous ionic hydrogenation and hydrogenolysis catalysis. Dalton Transactions 2006; (39) 4645-4653.

[50] Nakagawa Y, Shinmi Y, Koso S, Tomishige K. Direct hydrogenolysis of glycerol into 1,3-propanediol over rhenium-modified iridium catalyst. Journal of Catalysis 2010; 272 (2) 191-194.

[51] Chaminand J, Djakovitch L, Gallezot P, Marion P, Pinel C, Rosier C. Glycerol hydrogenolysis on heterogeneous catalysts. Green Chemistry 2004; 6 (8) 359-361.

[52] Shinmi Y, Koso S, Kubota T, Nakagawa Y, Tomishige K. Modification of Rh/SiO2 catalyst for the hydrogenolysis of glycerol in water. Applied Catalysis B: Environmental 2010; 94 (3-4) 318-326.

[53] Chia M, Pagan-Torres YJ, Hibbitts D, Tan Q, Pham HN, Datye AK, Neurock M, Davis RJ, Dumesic JA. Selective Hydrogenolysis of Polyols and Cyclic Ethers over Bi- 
functional Surface Sites on Rhodium-Rhenium Catalysts. Journal of the American Chemical Society 2011; 133 (32) 12675-12689.

[54] King DL, Zhang L, Xia G, Karim AM, Heldebrant DJ, Wang X, Peterson T, Wang Y. Aqueous phase reforming of glycerol for hydrogen production over $\mathrm{Pt}-\mathrm{Re}$ supported on carbon. Applied Catalysis B: Environmental 2010; 99 (1-2) 206-213.

[55] Qin L, Song M, Chen C. Aqueous-phase deoxygenation of glycerol to 1,3-propanediol over $\mathrm{Pt} / \mathrm{WO} / \mathrm{ZrO} 2$ catalysts in a fixed-bed reactor. Green Chemistry 2010; 12 (8) 1466-1472.

[56] Montassier C, Ménézo JC, Hoang LC, Renaud C, Barbier J. Aqueous polyol conversions on ruthenium and on sulphur-modified ruthenium. Journal of Molecular Catalysis 1991; 70 (1) 99-110.

[57] Feng J, Fu H, Wang J, Li R, Chen H, Li X. Hydrogenolysis of glycerol to glycols over ruthenium catalysts: Effect of support and catalyst reduction temperature. Catalysis Communications 2008; 9 (6) 1458-1464.

[58] Furikado I, Miyazawa T, Koso S, Kunimori K, Tomishige K. Catalytic performance of $\mathrm{Rh} / \mathrm{SiO}_{2}$ in glycerol reaction under hydrogen. Green Chemistry 2007; 9 (6) 582-588.

[59] Lahr DG, Shanks BH. Kinetic Analysis of the Hydrogenolysis of Lower Polyhydric Alcohols: Glycerol to Glycols. Industrial \& Engineering Chemistry Research 2003; 42 (22) $5467-5472$.

[60] Kusunoki Y, Miyazawa T, Kunimori K, Tomishige K. Highly active metal-acid bifunctional catalyst system for hydrogenolysis of glycerol under mild reaction conditions. Catalysis Communications 2005; 6 (10) 645-649.

[61] Miyazawa T, Kusunoki Y, Kunimori K, Tomishige K. Glycerol conversion in the aqueous solution under hydrogen over $\mathrm{Ru} / \mathrm{C}+$ an ion-exchange resin and its reaction mechanism. Journal of Catalysis 2006; 240 (2) 213-221.

[62] Miyazawa T, Koso S, Kunimori K, Tomishige K. Glycerol hydrogenolysis to 1,2-propanediol catalyzed by a heat-resistant ion-exchange resin combined with $\mathrm{Ru} / \mathrm{C}$. Applied Catalysis A: General 2007; 329 30-35.

[63] Miyazawa T, Koso S, Kunimori K, Tomishige K. Development of a Ru/C catalyst for glycerol hydrogenolysis in combination with an ion-exchange resin. Applied Catalysis A: General 2007; 318 (1) 244-251.

[64] Akiyama M, Sato S, Takahashi R, Inui K, Yokota M. Dehydration-hydrogenation of glycerol into 1,2-propanediol at ambient hydrogen pressure. Applied Catalysis A: General 2009; 371 (1-2) 60-66.

[65] Huang Z, Cui F, Kang H, Chen J, Xia C. Characterization and catalytic properties of the $\mathrm{CuO} / \mathrm{SiO}_{2}$ catalysts prepared by precipitation-gel method in the hydrogenolysis of glycerol to 1,2-propanediol: Effect of residual sodium. Applied Catalysis A: General 2009; 366 (2) 288-298. 
[66] Xia S, Yuan Z, Wang L, Chen P, Hou Z. Catalytic production of 1,2-propanediol from glycerol in bio-ethanol solvent. Bioresource technology 2012; 104 (1) 814-817.

[67] Balaraju M, Rekha V, Prasad PSS, Devi BLAP, Prasad RBN, Lingaiah N. Influence of solid acids as co-catalysts on glycerol hydrogenolysis to propylene glycol over Ru/C catalysts. Applied Catalysis A: General 2009; 354 (1-2) 82-87.

[68] Vasiliadou ES, Heracleous E, Vasalos IA, Lemonidou AA. Ru-based catalysts for glycerol hydrogenolysis-Effect of support and metal precursor. Applied Catalysis B: Environmental 2009; 92 (1-2) 90-99.

[69] Sato S, Akiyama M, Takahashi R, Hara T, Inui K, Yokota M. Vapor-phase reaction of polyols over copper catalysts. Applied Catalysis A: General 2008; 347 (2) 186-191.

[70] Sato S, Akiyama M, Inui K, Yokota M. Selective Conversion of Glycerol into 1,2-Propanediol at Ambient Hydrogen Pressure. Chemistry Letters 2009; 38 (6) 560-561.

[71] Xia S, Yuan Z, Wang L, Chen P, Hou Z. Hydrogenolysis of glycerol on bimetallic Pd$\mathrm{Cu} /$ solid-base catalysts prepared via layered double hydroxides precursors. Applied Catalysis A: General 2011; 403 (1-2) 173-182.

[72] Amada Y, Shinmi Y, Koso S, Kubota T, Nakagawa Y, Tomishige K. Reaction mechanism of the glycerol hydrogenolysis to 1,3-propanediol over $\mathrm{Ir}-\mathrm{ReOx} / \mathrm{SiO}_{2}$ catalyst. Applied Catalysis B: Environmental 2011; 105 (1-2) 117-127.

[73] Johnstone RAW, Wilby AH, Entwistle ID. Heterogenous Catalytic Transfer Hydrogenation and Its Relation to Other Methods for Reduction of Organic Compounds. Chemical Reviews 1985; 85 (2) 129-170.

[74] Thring RW, Chornet E, Overend RP. Thermolysis of Glycol Lignin in the Presence of Tetralin. Canadian Journal of Chemical Engineering 1993; 71 (1) 107-115.

[75] Kleinert M, Barth T. Towards a lignocellulosic Biorefinery: Direct One-Step Conversion of Lignin to Hydrogen-Enriched Biofuel. Energy Fuels 2008; 22 (2) 1371-1379.

[76] D’Hont E, Van de Vyver S, Sels BF, Jacobs PA. Catalytic glycerol conversion into 1,2propanediol in absence of added hydrogen. Chemical Communications 2008; (45) 6011-6012.

[77] Van de Vyver S, D'Hondt E, Sels BF, Jacobs PA. Preparation of Pt on NaY zeolite catalysts for conversion of glycerol into 1,2-propanediol. Studies in Surface Science and Catalysis 2010; 175 (1) 771-774.

[78] Huber GW, Cortright RD, Dumesic JA. Renewable alkanes by aqueous-phase reforming of biomass-derived oxygenates. AngewandteChemie-International Edition 2004; 43 (12) 1549-1551.

[79] Davda RR, Shabaker JW, Huber GW, Cortright RD, Dumesic JA. Aqueous-phase reforming of ethylene glycol on silica-supported metal catalysts. Applied Catalysis B: Environmental 2003; 43 (1) 13-26. 
[80] Wolfson A, Dlugy C, Shotland Y, Tavor D. Glycerol as solvent and hydrogen donor in transfer hydrogenation-dehydrogenation reactions. Tetrahedron letters 2009; 50 (43) 5951-5953.

[81] Bulushev DA, Ross JRH. Vapour phase hydrogenation of olefins by formic acid over a Pd/C catalyst. Catalysis Today 2011; 163 (1) 42-46.

[82] Aramendía MA, Borau V, Jiménez C, Marinas JM, Ruiz JR, Urbano FJ. Liquid-phase heterogeneous catalytic transfer hydrogenation of citral on basic catalysts. Journal of Molecular Catalysis A: Chemical 2001; 171 (1-2) 153-158.

[83] Musolino MG, Scarpino LA, Mauriello F, Pietropaolo R. Selective transfer hydrogenolysis of glycerol promoted by palladium catalysts in absence of hydrogen. Green Chemistry 2009; 11 (10) 1511-1513.

[84] Gandarias I, Requies J, Arias PL, Armbruster U, Martin A. Liquid-phase glycerol hydrogenolysis by formic acid over $\mathrm{Ni}-\mathrm{Cu} / \mathrm{Al}_{2} \mathrm{O}_{3}$ catalysts. Journal of Catalysis 2012; 290 (1) 79-89.

[85] Gandarias I, Arias PL, Fernández SG, Requies J, El Doukkali M, Güemez MB. Hydrogenolysis through catalytic transfer hydrogenation: glycerol conversion to 1,2-propanediol. Catalysis Today 2012; http://dx.doi.org/10.1016/j.cattod.2012.03.067. 